\title{
Laser-Assisted Removal of Graffiti from Granite: Advantages of the Simultaneous Use of Two Wavelengths
}

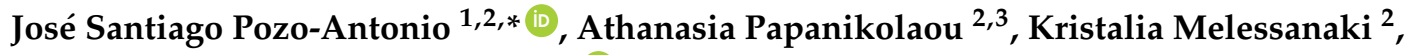 \\ Teresa Rivas ${ }^{1}$ and Paraskevi Pouli ${ }^{2}$ (D) \\ 1 Department de Enxeñaría de Recursos Naturais e Medioambiente, Universidade de Vigo, 36310 Vigo, Spain; \\ trivas@uvigo.es \\ 2 Institute of Electronic Structure and Laser, Foundation for Research and Technology-Hellas (IESL-FORTH), \\ 70013 Crete, Greece; athanasiap08@gmail.com (A.P.); alina@iesl.forth.gr (K.M.); ppouli@iesl.forth.gr (P.P.) \\ 3 Department of Physics, University of Crete, 70013 Crete, Greece \\ * Correspondence: ipozo@uvigo.es; Tel.: +34-986-130-211
}

Received: 27 February 2018; Accepted: 25 March 2018; Published: 28 March 2018

\begin{abstract}
Currently, removal of graffiti from stone monuments is a particularly challenging task. Lasers, being highly controllable and precise tools with minimal chemical waste, offer a key solution in this respect and a significant amount of research has been dedicated to this subject. Studies related to the laser cleaning of carbonate stones (such as limestone and marble) reported the extraction of the graffiti layer, although minimal damage to the substrate can be also detected. Recently, research efforts have been focused on the cleaning of granite, which is a complex stone due to its grained and polymineralic texture. Tests involving different wavelengths indicated that the effectiveness of the cleaning procedure is highly dependent on two components: The composition of the binding medium of the graffiti and the fissure system of the granite. In that direction, the aim of this paper is to investigate and to compare the cleaning effectiveness of two wavelengths emitted from a nanosecond (ns) Q-Switched Nd:YAG laser system (IR at $1064 \mathrm{~nm}$ and UV at $355 \mathrm{~nm}$ ), as well as their simultaneous application at different energy density ratios $F_{\mathrm{IR}} / F_{\mathrm{UV}}$. The effectiveness of this combined methodology has been shown in several other cases; i.e., for the removal of pollution crusts from carbonate stones (marble). For this study, three different in composition graffiti paints (blue, black, and silver) were applied on a fine-grained granite originating from the NW Iberian Peninsula. Prior to the irradiation tests, the damage thresholds of the granite, as well as the extraction thresholds of the graffiti, were determined. Then, several tests involving a variety of parameters (fluence value, number of pulses, etc.) were performed and the most satisfactory irradiation conditions from each individual wavelength as well as their combination were compared, based on graffiti extraction level and any damage induced on the granite forming minerals. The analytical techniques used for the evaluation were stereomicroscopy, color measurements in CIELAB and CIELCH color spaces, Fourier transform infrared spectroscopy (FTIR), scanning electron microscopy with energy dispersive X-ray spectroscopy (SEM-EDS) and confocal microscopy. The experiments indicated the superiority of the combined laser cleaning regarding blue and black graffiti extraction.
\end{abstract}

Keywords: granite; graffiti cleaning; laser cleaning; Nd:YAG

\section{Introduction}

Graffiti is one of the most immediate threats encountered on heritage monuments worldwide and its cleaning is considered by the entities responsible for the heritage protection as one of the most 
demanding conservation issues [1]. The necessity of methods to completely extract the graffiti paints safeguarding the original surfaces was discussed in scientific projects focused on the optimization of cleaning methodologies, as well as on the development of protective anti-graffiti coatings [1-6].

Graffiti is, by its nature, a particular over-layer to remove because of the presence of pigments of different color and chemistry, and also because its penetration into the stone bulk is inevitable. Conventional cleaning methods, involving the use of chemical products and mechanical tools, do not completely remove the paint and at the same time they can be rather aggressive to the stone surface [2]. Lately, laser radiation has been evaluated as a feasible alternative tool for the elimination of graffiti due to its high precision and control during cleaning, as well as the possibility for automated cleaning processes [7-14]. Recent studies have been focused on the determination of optimum laser cleaning parameters and procedures for graffiti paint removal [15-18].

Most studies refer to the laser removal of the commonly used graffiti paints on marble, limestone, sandstone, mortar, and brick substrates [16,19-21]. The fundamental and harmonic wavelengths (1064 nm, $532 \mathrm{~nm}$, and $355 \mathrm{~nm}$ ) of Nd:YAG laser systems have been employed and it was shown that the cleaning effectiveness varied for each case depending on the color of the graffiti, the laser wavelength, and the substrate material.

Nevertheless, the bibliography on laser cleaning of graffiti from granitic rocks is limited. Granitic rocks (considering as the richest plutonic rocks in quartz and K-feldspar) are commonly used to construct the architectural and archaeological heritage on the NW Iberian Peninsula. Commonly to the rest of the world, granitic monuments are highly exposed to graffiti vandalism thus urging research attention. Furthermore, their grained texture and polymineralic character pose several difficulties upon any cleaning attempt, including laser cleaning. Each forming mineral (quartz, K-feldspar, plagioclase, biotite, and muscovite) presents different absorption properties to laser light and upon irradiation different ablation effects may be induced, thus jeopardizing the cleaned surface. This particularity has been discussed upon initial experiments to remove over-layers from granite. Specifically Delgado Rodrigues et al. [22] reported the damage and spallation of the biotite planes upon the removal of iron-black films by means of Nd:YAG lasers (1064 nm and $532 \mathrm{~nm}$ ) and, similarly, Ramil et al. [18] recently reported that the $355 \mathrm{~nm} \mathrm{Nd:YVO}$ laser cleaning effectiveness of granites depends on the relative amount of each silicate on the surface to be irradiated.

Regarding graffiti laser cleaning on granite, recent scientific works indicated that UV lasers $\left(\mathrm{Nd}: \mathrm{YVO}_{4}\right.$ and Nd:YAG at $355 \mathrm{~nm}$ ) can remove the paint layers from the surface of the stone, the chemical composition of the graffiti being the factor that influences the cleaning result the most. Moreover, the effectiveness of graffiti laser cleaning is hindered, similarly to all the stones, by the penetration depth of the paint into the fissures. Satisfactory results have been reported for blue, black, and red graffiti applied on a coarse-grained Rosa Porriño granite $[15,23]$, a fine-grained Vilachán granite [15] and a medium- to coarse-grained Silvestre granite [17]. Comparatively to conventional mechanical and chemical methods, laser cleaning was considered successful regarding the level of paint extraction; however, evidence of damage was found on the granite forming minerals, such as melting of the biotite grains, fracturing of the quartz grains and, in case of the black paint removal, a possible change in the hydration state of the iron oxides and oxyhydroxides present into the fissures $[15,17,23]$. Ramil et al. [18], in an attempt to overcome the limitations posed by the polymineralic nature of the granite employed multi-pulse scanning irradiation protocols and reported that (1) all graffiti colors were satisfactory removed from quartz and K-feldspar grains with $0.1-0.2 \mathrm{~J} \cdot \mathrm{cm}^{-2}$; (2) the efficiency of paint removal from plagioclase grains depended on the color and was achieved for laser fluence values from 0.1 to $1.0 \mathrm{~J} \cdot \mathrm{cm}^{-2}$; and (3) melting features were detected on biotite grains even for fluence values as low as the recorded graffiti removal threshold $\left(0.06 \mathrm{~J} \cdot \mathrm{cm}^{-2}\right)$. Note that experiments to remove silver graffiti were not satisfactory: A translucent film, rich in aluminum particles and easily visible under naked eye was detected on the laser treated surfaces [15].

To overcome potential damages to the different granite minerals and to achieve a satisfactory cleaning result, further research is required, and, in this respect, other laser cleaning methodologies 
should be investigated. The simultaneous use of two laser wavelengths that are differently absorbed by the involved materials was thus considered. Such an approach may also circumvent other side effects that have been reported upon laser cleaning experiments of graffiti, i.e., yellowing observed because of $1064 \mathrm{~nm}$ irradiation of sandstone to remove nitrocellulose, acrylic and alkyd paints [16]. The tests designed and performed in the present study are based on a methodology developed for the removal of black crusts from different stone substrates [12,24] and rely on the simultaneous use of the fundamental $(1064 \mathrm{~nm})$ and the third harmonic $(355 \mathrm{~nm})$ wavelengths of a Q-switched Nd:YAG laser at various fluence ratios $\left(F_{\mathrm{IR}} / F_{\mathrm{UV}}\right)$. The presented methodology was adjusted for the specific over-layer and substrate materials, and in this respect the cleaning effect of each wavelength was investigated based on its individual action and as a part of the combined beam. The best results obtained for each wavelength and their simultaneous use were compared and discussed with respect to the level of graffiti extraction and damage induced to the granite-forming minerals.

\section{Materials and Methods}

\subsection{Granite and Glass Slabs}

One of the most common granitic stones encountered in the cultural heritage of NW Iberian Peninsula, commercially called as Vilachán, was used. It is a fine-grained panallotriomorphic heterogranular granite [25], composed of quartz (47\%), potassium feldspar $(10 \%)$, plagioclase $(15 \%)$, biotite $(7 \%)$, muscovite $(18 \%)$ and accessory minerals (3\%). The grain size ranges between $2 \mathrm{~mm}$ and $0.3 \mathrm{~mm}$. Open porosity (accessibility to water following [26]) is $2.82 \%$. Ten $10 \mathrm{~cm} \times 10 \mathrm{~cm} \times 2 \mathrm{~cm}$ slabs were used: One reference slab to determine the damage thresholds of the granite and nine painted slabs to determine the optimum laser parameters and to evaluate the results for the different graffiti.

Moreover, three $10 \mathrm{~cm} \times 10 \mathrm{~cm} \times 0.5 \mathrm{~cm}$ glass slabs were used to determine the extraction thresholds of the graffiti paints.

\subsection{Spray Graffiti Paints and Painting Procedure}

Three spray graffiti paints by Montana Colors ${ }^{\circledR}$ (Barcelona, Spain), already characterized in [15], were selected. Graphite black (RAL code: R-9011), Ultramarine blue (R-5002) and Silver chrome (R-7001) have a high content of carbon, over $50 \%$. As reported in $[15,17]$ blue and black graffiti paints have an organic base of alkyd and polyester type, while silver chrome has an organic base of polyethylene type.

Three granite slabs and one glass slab were painted with each graffiti color. The graffiti application was performed with the following methodology: An initial layer was sprayed for $10 \mathrm{~s}$ at distance of $15 \mathrm{~cm}$ from the sample. After $24 \mathrm{~h}$ the same procedure was repeated and then, the samples were air-dried at laboratory conditions $\left(18 \pm 5{ }^{\circ} \mathrm{C}\right.$ and $\left.80 \% \pm 10 \% \mathrm{RH}\right)$ for 1 month. The thickness of these paint films is estimated to be below $50 \mu \mathrm{m}$.

\subsection{Laser System and Parameters}

The system used for the laser cleaning trials was a BMI Q-switched Nd:YAG system (5022 DNS10 serie, B.M. Industries, Le Plessis-Trévise, France) modified by the IESL-FORTH to operate at the fundamental $(1064 \mathrm{~nm})$ and the third harmonic $(355 \mathrm{~nm})$ wavelengths individually, and simultaneously [12]. The pulse length was $6.5 \mathrm{~ns}$ and the repetition rate was $1-3 \mathrm{~Hz}$. The laser beams were focused to a spot of approximately $2 \mathrm{~mm} \times 2 \mathrm{~mm}$ as measured on a polyvinylchloride-unplasticized PVC (LS428734 VCS, Goodfellow, Huntingdon, UK) sheet with $0.5 \mathrm{~mm}$ thickness. All irradiation tests were performed in dry conditions.

An automated XYZ system for moving the object in front of the laser beam was designed at IESL-FORTH (Heraklion, Crete, Greece) for the purpose of these experiments. The software, customarily developed by means of LabVIEW, allows the operator to define the area to be treated and control parameters related to the number of pulses applied at the same spot and their relative positioning when the laser beam is moving to an adjacent area (percentage (\%) of overlapping). 


\subsection{Experimental Methodology}

Initially, ablation thresholds of the black, blue, and silver graffiti on painted glasses and the unpainted granite were determined. For this purpose, a series of spot irradiation experiments were performed on these reference samples. These tests were performed for each wavelength $(1064 \mathrm{~nm}$ and $355 \mathrm{~nm}$ ) to specify the range of fluence values to be used. The ablation (extraction) threshold of the graffiti corresponds to the lowest fluence value that induces changes on the material and it is calculated by recording any modification on the surface of the graffiti (color changes, texture modifications, etc.) upon single-pulse irradiation at increasing fluence values. Fluence $(F)$ is expressed by means of: $F=E / S$ in $\mathrm{J} \cdot \mathrm{cm}^{-2}$, being $E$ the output energy of the laser system and $S$ the surface of the irradiation area. The extraction thresholds of the graffiti paints were determined through single pulse irradiation tests using varying fluence values from 0.1 up to $1.0 \mathrm{~J} \cdot \mathrm{cm}^{-2}$ (see Table 1) on painted glass slabs. The use of glass slabs was considered in order to study the extraction of the graffiti paint layer without any side-effects due to the penetration of its binding medium into the stone substrate. The ablation (damage) threshold of the granite was defined as the lowest fluence value that causes no alterations to biotite (such as melting, opening of the exfoliation planes or extraction of grains). Biotite is the most sensitive mineral to the laser beam radiation [18,22] and this susceptibility is related to its high optical absorption along with its relatively low melting point $650{ }^{\circ} \mathrm{C}$ [27]. However, the fine grain size of the Vilachán granite studied herein (as can be seen in Figure 1a), makes unfeasible the determination of the ablation threshold through single spot irradiation. For this reason, areas of $1 \mathrm{~cm} \times 1 \mathrm{~cm}$ were irradiated using 1-2 laser pulses. The fluence values tested ranged from $0.6 \mathrm{up}$ to $2.3 \mathrm{~J} \cdot \mathrm{cm}^{-2}$ for $1064 \mathrm{~nm}$ and from 0.2 up to $1.0 \mathrm{~J} \cdot \mathrm{cm}^{-2}$ for $355 \mathrm{~nm}$ (see Table 1) in close relation to the observed damage for each wavelength.

Table 1. Extraction thresholds for the three graffiti paints and damage thresholds for granite at $1064 \mathrm{~nm}$ and $355 \mathrm{~nm}$. Range of tested fluences for both wavelengths for the unpainted granite and the graffiti painted glass slabs are also shown together with the calculated theoretical threshold values for the three paints (described in Section 3.2).

\begin{tabular}{|c|c|c|c|c|}
\hline Sample & Wavelength (nm) & $\begin{array}{l}\text { Range of Tested Fluence } \\
\text { Values }\left(\mathrm{J} \cdot \mathrm{cm}^{-2}\right)\end{array}$ & $\begin{array}{l}\text { Threshold } \\
\left(\mathrm{J} \cdot \mathrm{cm}^{-2}, 1 \mathrm{p}\right)\end{array}$ & $\begin{array}{c}\text { Theoretical } \\
\text { Threshold }\left(\mathrm{J} \cdot \mathrm{cm}^{-2}\right)\end{array}$ \\
\hline \multirow{2}{*}{ Granite } & 1064 & $0.6-2.3$ & 1.1 & - \\
\hline & 355 & $0.2-1.0$ & 0.7 & - \\
\hline \multirow{2}{*}{ Blue Graffiti } & 1064 & \multirow{6}{*}{$0.1-1.0$} & 0.5 & $0.333 \pm 0.048$ \\
\hline & 355 & & $<0.1$ & $0.027 \pm 0.001$ \\
\hline \multirow{2}{*}{ Black Graffiti } & 1064 & & $<0.1$ & $0.009 \pm 0.002$ \\
\hline & 355 & & $<0.1$ & $0.012 \pm 0.001$ \\
\hline \multirow{2}{*}{ Silver Graffiti } & 1064 & & $<0.1$ & $0.030 \pm 0.001$ \\
\hline & 355 & & $<0.1$ & $0.011 \pm 0.001$ \\
\hline
\end{tabular}

The identified ablation thresholds were then validated on the real scenario (graffiti on granite), and cleaning methodologies (fluence values, number of pulses and scanning parameters) were determined for the investigated samples. Each laser parameter was tested through the irradiation of spots and areas $(1 \mathrm{~cm} \times 1 \mathrm{~cm})$ with varying number of pulses and was preliminary evaluated. The results provided the basis for the determination of the $F_{\mathrm{IR}} / F_{\mathrm{UV}}$ ratios to be tested for the simultaneous combination of the two wavelengths. An important limitation in this respect is that the total fluence value $\left(F_{\text {total }}=F_{\mathrm{IR}}+F_{\mathrm{UV}}\right)$, for each $F_{\mathrm{IR}} / F_{\mathrm{UV}}$ ratio, must not exceed the ablation threshold of the granite for each of the individual wavelengths $[12,13]$.

The conditions that allowed us to obtain the most satisfactory cleaning results were selected and applied on areas of about $4 \mathrm{~cm} \times 4 \mathrm{~cm}$ to allow a detailed and multi-analytical evaluation of the paint extraction and the possible damage induced on the rock. 


\subsection{Analytical Techniques}

A Nikon SMZ800 stereomicroscope (Tokyo, Japan) and a Dino-Lite Digital microscope (New Taipei City, Taiwan) were employed to determine the ablation thresholds of the graffiti paints on glass slabs, the damage thresholds of the reference granite as well as to evaluate the cleaning level of the painted granitic samples, on both irradiated areas of $1 \mathrm{~cm} \times 1 \mathrm{~cm}$ and $4 \mathrm{~cm} \times 4 \mathrm{~cm}$. It was also possible to assess the damages induced on the rock substrate, when the irradiation conditions exceeded the threshold fluence values, as for example grain extraction, melting or other alteration features (opening of biotite exfoliation planes etc.). This preliminary assessment allowed us to identify the most satisfactory conditions for further evaluation.

The composition, morphology, and thickness of the graffiti layers before and after laser radiation as well as the damages in the granite-forming minerals after laser treatment were further evaluated under scanning electron microscopy (SEM). For this purpose, small fragments (approximately $3 \mathrm{~cm}^{2}$ ) from the painted surfaces before and after the laser irradiation, as well as their cross sections (embedded in resin and polished), were analyzed. A Philips XL30 SEM (Amsterdam, The Netherlands) coupled with an energy dispersive X-ray spectrometry (EDS) (Oxford Inca Energy 300 SEM, Oxfordshire, UK) was used; both secondary electrons (SE) and backscattered electrons (BSE) modes were applied to observe the samples. Carbon-coated samples were visualized at an accelerating potential of $15-20 \mathrm{kV}$, a working distance of 9-11 $\mathrm{mm}$ and specimen current of $\sim 60 \mathrm{~mA}$.

The roughness variation of the surfaces due to its interaction with the laser beam was evaluated by confocal microscopy (PLu 2300 Sensofar ${ }^{\circledR}$ optical imaging profiler, Co Meath, Ireland) in the $4 \mathrm{~cm} \times 4 \mathrm{~cm}$ treated areas. Images of the treated surface were collected using an EPI 10X-N objective a speed of $1 \times$, an overlapping of $25 \%$, a depth resolution of $2 \mathrm{~mm}$ and a lateral resolution of $1 \mathrm{~nm}$. The dimension of the measured area was $4.14 \mathrm{~mm} \times 3.10 \mathrm{~mm}$. After the data acquisition, it was processed with Gwyddion 2.47 software to calculate the arithmetic average height, $R_{\mathrm{a}}$ [28]. Standard deviation values were also calculated. Roughness data of the unpainted granite and the painted granite with the three colors were used as a reference and were compared with the values recorded from the irradiated areas. In addition, roughness measurements were also employed for the identification of the ablation thresholds.

Color measurements in CIELAB and CIELCH color spaces [29], performed with a Minolta spectrophotometer CM-700d (Osaka, Japan) equipped with CM-S100w (SpectraMagicTM NX) software, were taken on the uncoated granite and the graffiti painted granite samples after the laser treatment. For each sample, the area of $4 \mathrm{~cm} \times 4 \mathrm{~cm}$ was used, taking a total of 15 random measurements per area to obtain statically consistent results [30]. $L^{*}$ (lightness varying from black to white), polar coordinates $a^{*}$ (red-green) and $b^{*}$ (yellow-blue) and $C^{*}$ ab (chroma, saturation or color purity) were obtained in specular component included (SCI) mode, for a spot diameter of $8 \mathrm{~mm}$, using illuminant D65 and with an observer angle of $10^{\circ}$. In order to assess the cleaning effectiveness, color differences $\left(\Delta L^{*}, \Delta a^{*}, \Delta b^{*}\right.$, $\left.\Delta C^{*}{ }_{\mathrm{ab}}\right)$ and global color change $\left(\Delta E^{*}{ }_{a b}=\sqrt{\left(\Delta L^{*}\right)^{2}+\left(\Delta a^{*}\right)^{2}+\left(\Delta b^{*}\right)^{2}}\right)$ were computed considering the color of the unpainted granite surface as reference color (procedure is based on the [29]. Therefore, the higher the $\Delta E_{\mathrm{ab}}^{*}$ the greater the laser effectiveness in removing the graffiti.

Fourier transform infrared spectroscopy (FTIR) was applied to detect graffiti remains after the laser treatment in small fragments (approximately $3 \mathrm{~cm}^{2}$ ), based on the identification of functional groups previously assigned to the graffiti paints. FTIR data were collected in reflectance mode using a Thermo Nicolet ${ }^{\circledR} 6700$ (ThermoFisher, Waltham, MA, USA) in the $4000-400 \mathrm{~cm}^{-1}$ region, with $4 \mathrm{~cm}^{-1}$ resolution.

\section{Results}

\subsection{Damage Thresholds of the Vilachán Granite}

The damage thresholds of the granite subjected to both wavelengths were determined by means of stereomicroscopy, roughness measurements and SEM. Figure 1 shows several micrographs of the granite subjected to $1064 \mathrm{~nm}$ laser irradiation at different fluence values; micrographs of the 
untreated granite (Figure 1a) are also shown for comparative purposes. The laser irradiation at fluence values up to $1.1 \mathrm{~J} \cdot \mathrm{cm}^{-2}$ (Figure $1 \mathrm{~b}$ ) did not cause visible damage in the granite: The characteristic yellowish-brown color of stone remained intact (Figure 1(b1)) and no changes were found on the biotite grains (Figure 1(b2,b3)). Conversely, the granite surfaces subjected to $1064 \mathrm{~nm}$ laser irradiation at fluence values above $1.2 \mathrm{~J} \cdot \mathrm{cm}^{-2}$ (Figure $1 \mathrm{c}, \mathrm{d}$ ) presented several signs of damage:

- The characteristic yellowish-brown color of the rock lost intensity, as detected by stereomicroscopy (Figure 1(c1,d1)).

- $\quad$ Biotite grains melted, as seen by SEM, especially for high fluence values (Figure 1(c3,d3)).

- The roughness of the surface was modified especially when high fluence values were employed; SEM micrographs at low magnification (Figure $1(\mathrm{c} 2, \mathrm{~d} 2)$ ) show wide and deep valleys on the rock surface upon extreme irradiation conditions. The surface roughness $\left(R_{\mathrm{a}}\right)$ was increased due to the extraction of mineral grains (also verified by stereomicroscopy and SEM-Figure 1(c1,d1) from $14.89 \pm 0.79 \mu \mathrm{m}$ (reference surface-Figure 1(a1) up to $25.20 \pm 0.63 \mu \mathrm{m}$ (at $1.5 \mathrm{~J} \cdot \mathrm{cm}^{-2}$-Figure $1(\mathrm{~d} 1)$ ).
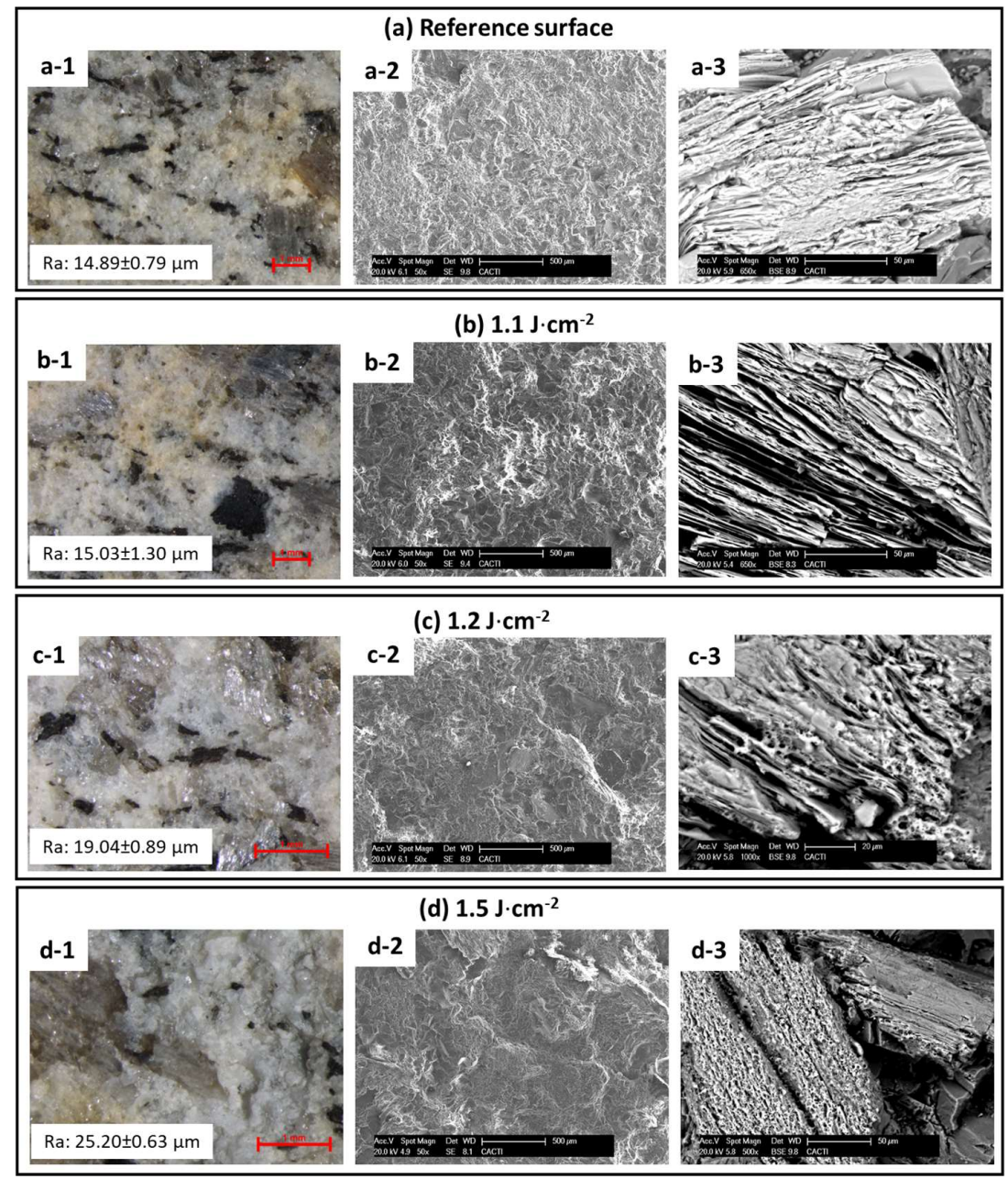

Figure 1. Micrographs obtained by means of stereomicroscopy (1) and SEM (2 and 3) of the reference granite (a) and the granite surfaces treated with a ns Nd:YAG laser at $1064 \mathrm{~nm}$ at different fluence values: (b) $1.1 \mathrm{~J} \cdot \mathrm{cm}^{-2}$; (c) $1.2 \mathrm{~J} \cdot \mathrm{cm}^{-2}$ and (d) $1.5 \mathrm{~J} \cdot \mathrm{cm}^{-2}$. Images numbered with 1 show the arithmetic average height, $\mathrm{Ra}(\mu \mathrm{m})$ taken with confocal microscopy. Images numbered with 3 depict the biotite crystals in detail, in order to describe the absence or the presence of indicative melting textures. The scale bar of stereomicrographs is $1 \mathrm{~mm}$. 
Therefore, the damage threshold of the Vilachán fine-grained granite for the IR (1064 nm) wavelength was determined to be $1.1 \mathrm{~J} \cdot \mathrm{cm}^{-2}$ (Table 1). Following the same evaluation protocol for the $355 \mathrm{~nm}$, the damage threshold was defined to be $0.7 \mathrm{~J} \cdot \mathrm{cm}^{-2}$ (Table 1).

\subsection{Extraction Thresholds of the Graffiti Paints}

The extraction thresholds of black and silver graffiti were determined through stereomicroscopic observation to be lower than $0.1 \mathrm{~J} \cdot \mathrm{cm}^{-2}$ for both wavelengths (Figure 2, Table 1). In contrast the threshold for the blue graffiti varied depending on the laser wavelength; at $355 \mathrm{~nm}$ it was defined to be below $0.1 \mathrm{~J} \cdot \mathrm{cm}^{-2}$ and at $1064 \mathrm{~nm} 0.5 \mathrm{~J} \cdot \mathrm{cm}^{-2}$ (Figure 2, Table 1), as it was shown that paint extraction initiates above the $0.6 \mathrm{~J} \cdot \mathrm{cm}^{-2}$ (Figure 2). This difference could be associated to the different laser absorption properties of the blue paint in the two laser ablation regimes. It has also to be noted that upon the irradiation tests on the painted glass slabs, the graffiti paint was removed leaving behind a thin translucent film possibly attributed to remaining binding medium. Different results have been noticed for the painted granite as will be discussed later (Section 3.5)

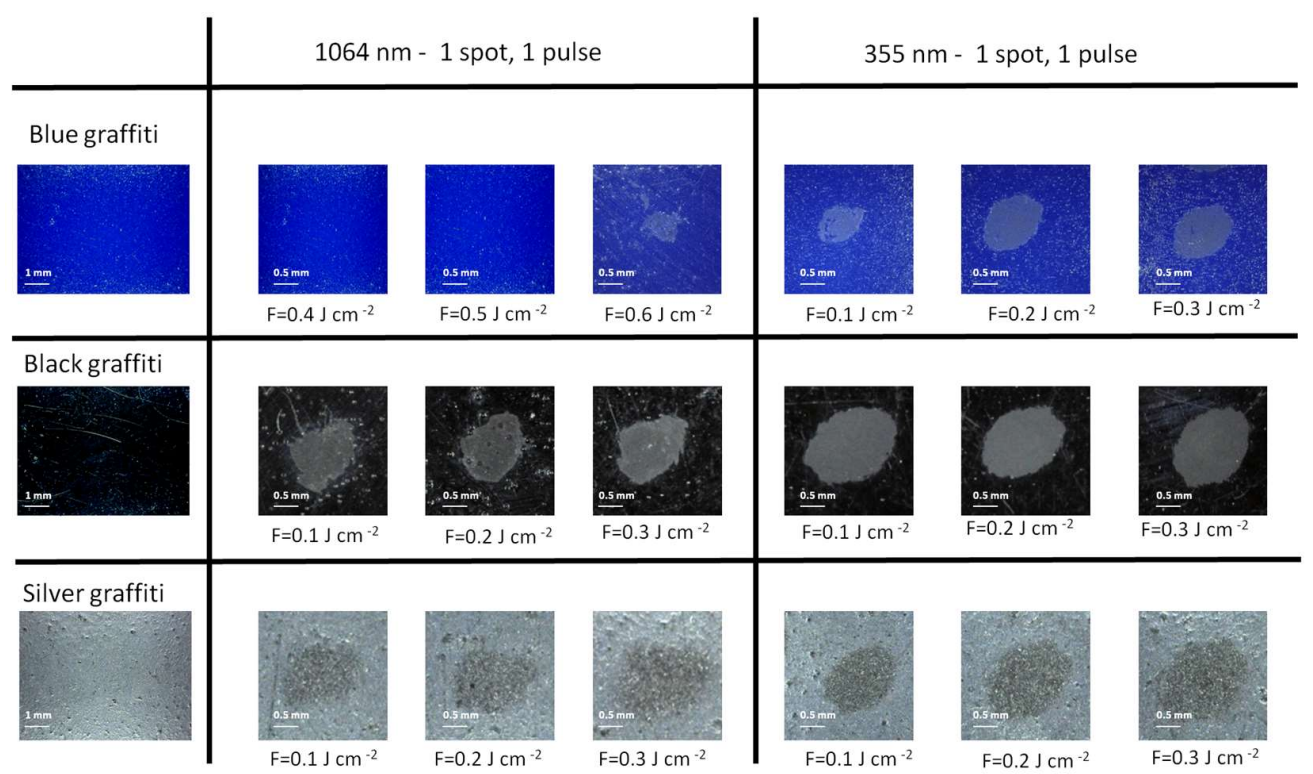

Figure 2. Micrographs taken under stereomicroscopy of the single pulse spots performed at different fluence values $(F)$ on the graffiti painted glass slabs. Results for the two wavelengths evaluated ( $355 \mathrm{~nm}$ and $1064 \mathrm{~nm}$ ) are shown (For interpretation of the references to color, the reader is referred to the web version of this article).

The ablation thresholds have also been calculated by measuring the pulse energy for every fluence value used along with the corresponding spot size, as recorded on the three glass slabs covered with graffiti. For Gaussian beams Liu et al. [31] reported that the threshold energy $\left(E_{\text {thr }}\right)$ can be calculated through the semi logarithmic plot of the energy $(E)$ dependence on the spot size (of $d$ diameter). The beam radius $w_{\mathrm{o}}$, at the 1/e of the Gaussian beam distribution, corresponds to the slope of the linear fit of the data, while the intercept at the value of threshold Energy described by the relationship: $d^{2}=2 w_{o}^{2}\left(\ln \left(E_{\mathrm{thr}}\right)-\ln (E)\right)$. The ablation thresholds calculated agree with the microscopic determination of the fluence and are also shown in Table 1.

\subsection{Characterization of Graffiti Layers on Granite}

Visualization of the samples under SEM indicated that, although the graffiti paints formed a continuous film on the stone, different textures could be discriminated depending on the composition of the paint (Figure 3): 
- Blue graffiti (Figure 3a and its EDS spectrum). These films, rich in $\mathrm{C}, \mathrm{Si}, \mathrm{Ti}$ and $\mathrm{Mg}$, were characterized by a mixture of scales of different sizes and shapes embedded in a C-rich matrix.

- Black graffiti (Figure 3b and its EDS spectrum) appeared as a homogeneous film composed exclusively of carbon.

- Silver graffiti (Figure $3 c$ and its EDS spectrum) was composed of laminar shaped particles $(<10 \mu \mathrm{m}$ in size) rich in $\mathrm{Al}$.
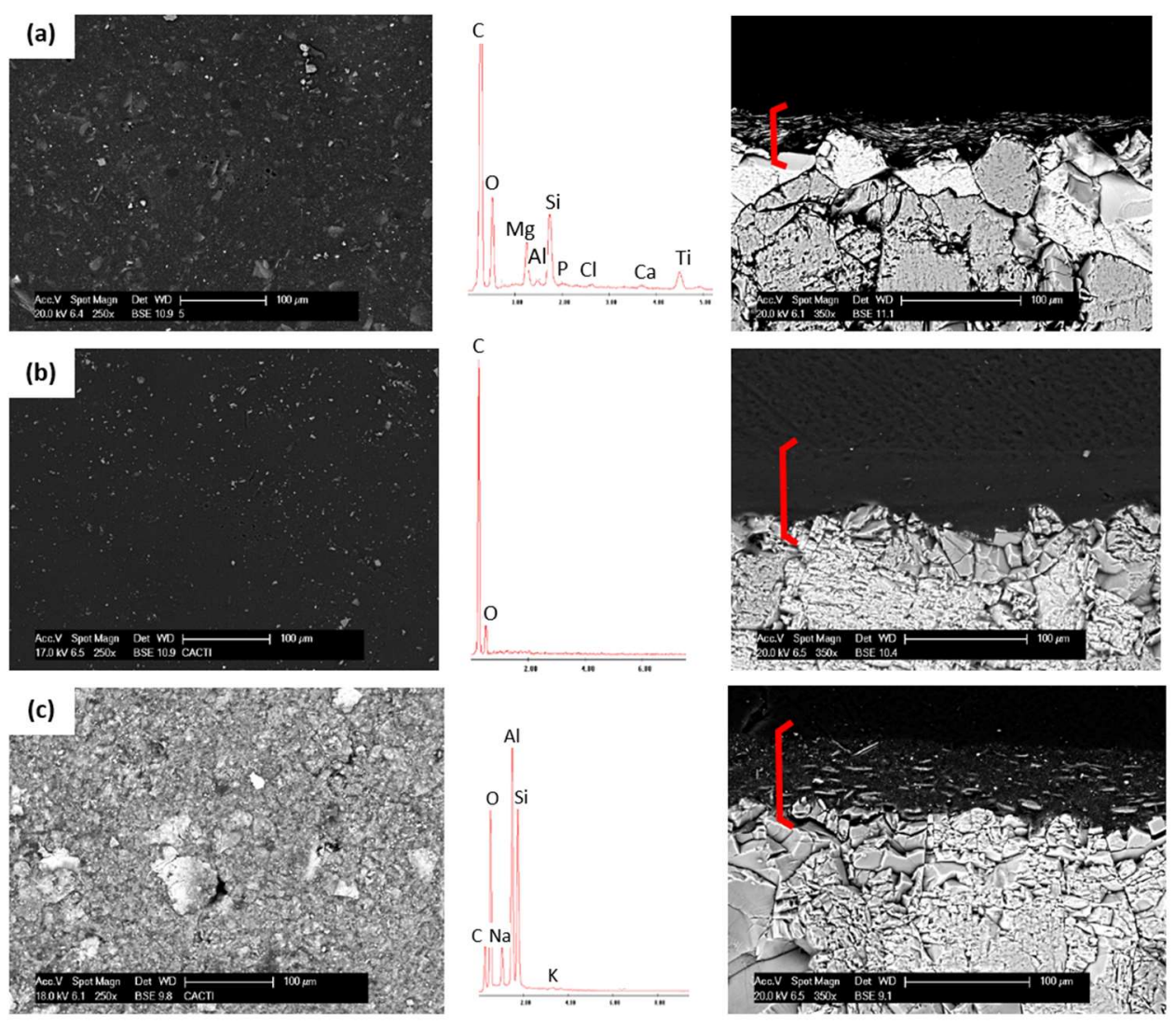

Figure 3. SEM micrographs of the graffiti layers on the granite from the surface (left) and the corresponding cross-sections (right). EDS spectra of the respective paints are also shown: (a) blue; (b) black and (c) silver graffiti paints.

The thickness of the graffiti layers varied depending of the color: $20 \pm 10 \mu \mathrm{m}$ for blue (Figure 3a) and $40 \pm 10 \mu \mathrm{m}$ for black and silver graffiti paints (Figure $3 \mathrm{~b}, \mathrm{c}$ ).

\subsection{Determination of the Irradiation Conditions}

Taking into account the determined damage thresholds of the granite and the extraction thresholds of the graffiti films, the cleaning conditions for the single wavelengths and for the combination with different $F_{\mathrm{IR}} / F_{\mathrm{UV}}$ ratios were planned (Table 2). Areas of $1 \mathrm{~cm}^{2}$ were irradiated using a variable number of pulses. The number of pulses for the graffiti samples was decided based on the different absorption properties of each color and also the thickness of the paint layer on the granite. 
Table 2. Irradiation conditions for the extraction of blue, black, and silver graffiti paints from the Vilachán granite.

\begin{tabular}{|c|c|c|c|}
\hline \multicolumn{4}{|c|}{ Single Wavelength Irradiation } \\
\hline Wavelength (nm) & $\begin{array}{l}\text { Fluence Values Tested } \\
\left(\mathrm{J} \cdot \mathrm{cm}^{-2}\right)\end{array}$ & \multicolumn{2}{|c|}{$\begin{array}{l}\text { Selected Conditions per Graffiti Color: } \\
\text { Fluence Values in } \mathrm{J} \cdot \mathrm{cm}^{-2} \text { (Number of Pulses) }\end{array}$} \\
\hline \multirow{3}{*}{1064} & \multirow{3}{*}{$0.4-1.2$} & Blue & $1.0(150)$ \\
\hline & & Black & $1.0(28)$ \\
\hline & & Silver & $0.5(9)$ \\
\hline \multirow{3}{*}{355} & \multirow{3}{*}{$0.2-1.0$} & Blue & $0.4(90)$ \\
\hline & & Black & $0.4(60)$ \\
\hline & & Silver & $0.5(9)$ \\
\hline \multicolumn{4}{|c|}{ Irradiation Using the Two Wavelengths Simultaneously } \\
\hline$F_{\mathrm{IR}} / F_{\mathrm{UV}}$ Ratio & $\begin{array}{c}\text { Fluence Values Tested } \\
\left(\mathrm{J} \cdot \mathrm{cm}^{-2}\right)\end{array}$ & \multicolumn{2}{|c|}{$\begin{array}{l}\text { Selected Conditions per Graffiti Color: } \\
\text { Fluence Values in } \mathrm{J} \cdot \mathrm{cm}^{-2} \text { (Number of Pulses) }\end{array}$} \\
\hline \multirow{3}{*}{$1 / 1$} & $0.2 / 0.2$ & - & - \\
\hline & $0.3 / 0.3$ & - & - \\
\hline & $0.4 / 0.4$ & - & - \\
\hline \multirow{4}{*}{$1 / 3$} & \multirow{2}{*}{$0.1 / 0.3$} & Blue & $0.1 / 0.3(27)$ \\
\hline & & Black & $0.1 / 0.3(18)$ \\
\hline & $0.2 / 0.6$ & - & - \\
\hline & $0.3 / 0.9$ & - & - \\
\hline \multirow{4}{*}{$3 / 1$} & \multirow{2}{*}{$0.3 / 0.1$} & Black & 0.3/0.1 (18) \\
\hline & & Silver & $0.3 / 0.1(12)$ \\
\hline & $0.6 / 0.2$ & - & - \\
\hline & $0.9 / 0.3$ & - & - \\
\hline
\end{tabular}

\subsection{Evaluation of the Graffiti Laser Cleaning-Tests}

Stereomicroscopic observation on the $1 \mathrm{~cm}^{2}$ treated areas (Figure $4 \mathrm{~b}-\mathrm{k}$ ), allowed us to identify the most satisfactory cleaning conditions (for each wavelength alone and their combination, see Table 2), in terms of graffiti extraction with minimum damage to the stone. These conditions were then selected to be applied in areas of $4 \mathrm{~cm} \times 4 \mathrm{~cm}$, for further analysis whose results comparatively to the original unpainted surface (Figure 4a) are discussed hereafter:

- Blue graffiti (Figure $4 \mathrm{~b}-\mathrm{d}$ ). In the $1064 \mathrm{~nm}$ regime, the best laser cleaning result was obtained with 150 pulses at $1 \mathrm{~J} \cdot \mathrm{cm}^{-2}$, although blue remains were still visible. In the $355 \mathrm{~nm}$ regime, 90 pulses at $0.4 \mathrm{~J} \cdot \mathrm{cm}^{-2}$ resulted into satisfactory cleaning. The best condition for the simultaneous application of both wavelengths was achieved with the $F_{\mathrm{IR}} / F_{\mathrm{UV}}$ ratio $1 / 3$ and fluence values of 0.1 and $0.3 \mathrm{~J} \cdot \mathrm{cm}^{-2}$ respectively (27 pulses). Irradiation involving $355 \mathrm{~nm}$ (either alone or in combination with the $1064 \mathrm{~nm}$ ) always removed the graffiti paint; however, the characteristic yellowish-brown color of the rock appeared faded/altered when compared to the reference surface.

- Black graffiti (Figure 4e-h). Both laser beams removed the black graffiti layer efficiently. The most favorable results were obtained at $1064 \mathrm{~nm}$ with 28 pulses at $1 \mathrm{~J} \cdot \mathrm{cm}^{-2}$ and, at $355 \mathrm{~nm}$, with 60 pulses at $0.4 \mathrm{~J} \cdot \mathrm{cm}^{-2}$. Interestingly, the simultaneous application of both wavelengths gave similar results for the ratios $1 / 3$ and 3/1: Specifically, the area irradiated with $F_{\mathrm{IR}} / F_{\mathrm{UV}}=0.3 / 0.1 \mathrm{~J} \cdot \mathrm{cm}^{-2}$ (18 pulses) appeared visually similar to the one cleaned with $F_{\mathrm{IR}} / F_{\mathrm{UV}}=0.1 / 0.3 \mathrm{~J} \cdot \mathrm{cm}^{-2}$ (18 pulses). Regarding the damage on the granite, the yellowish color of the rock was intensified after the irradiation at $1064 \mathrm{~nm}$; this same effect, although not as intense, occurred with the combined beams. Conversely, the irradiation with $355 \mathrm{~nm}$ caused a slight fading of the original color of the stone.

- Silver graffiti (Figure 4i-k). None of the experiments were able to eliminate silver paint. Moreover, in contrast to the irradiation of the other graffiti paints, an intense ablation plume was observed during the irradiation. The treated surfaces appeared darker than the untreated rock; a continuous film (in which remnants of silver color were clearly identified) was detected by stereomicroscopy on the surfaces cleaned at $355 \mathrm{~nm}$. Despite the unsatisfactory cleaning outcome, several parameters 
were selected to be further analytically examined aiming to approach the reason for such a result; 9 pulses of $0.5 \mathrm{~J} \cdot \mathrm{cm}^{-2}$ for the $1064 \mathrm{~nm}$ and $355 \mathrm{~nm}$ individually and 12 pulses of $F_{\mathrm{IR}} / F_{\mathrm{UV}}=0.3 / 0.1 \mathrm{~J} \cdot \mathrm{cm}^{-2}$ for their combination with a $F_{\mathrm{IR}} / F_{\mathrm{UV}}$ ratio $3 / 1$.
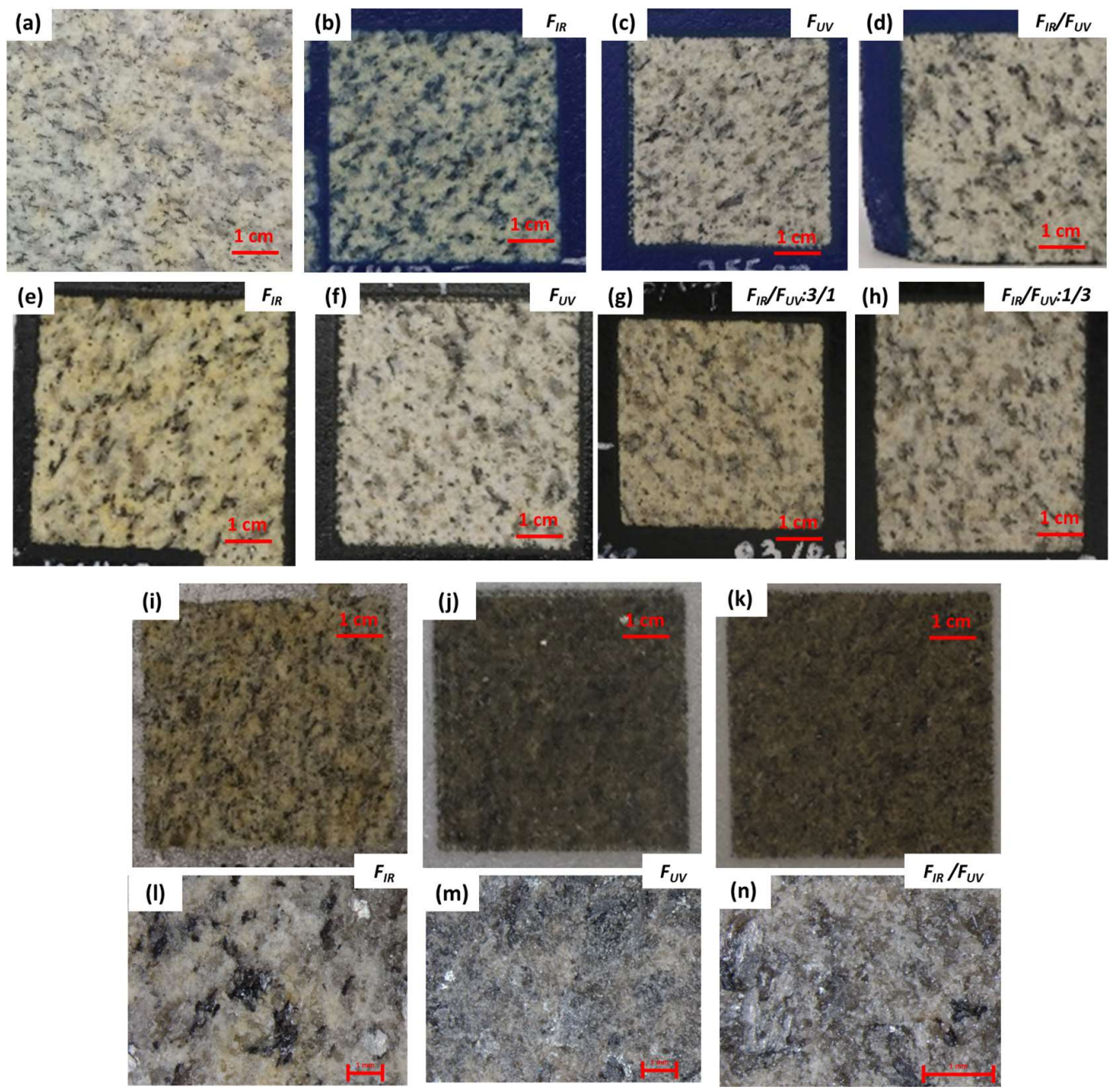

Figure 4. Digital photographs (scale bar of $1 \mathrm{~cm}$ ) of reference granite $(\mathbf{a})$; blue $(\mathbf{b}-\mathbf{d})$; black $(\mathbf{e}-\mathbf{h})$ and silver (i-k) painted samples treated with the selected conditions at $1064 \mathrm{~nm}$ (IR), $355 \mathrm{~nm}$ (UV) and their combination. Detailed irradiation conditions are shown in Table 2. For silver graffiti, detailed images taken with stereomicroscopy (scale bar of $1 \mathrm{~mm}$ ) are also shown: $1064 \mathrm{~nm}$ (1); $355 \mathrm{~nm}(\mathbf{m})$ and their combination (n) (For interpretation of the references to color, the reader is referred to the web version of this article).

Colorimetric differences $\left(\Delta L^{*}, \Delta a^{*}, \Delta b^{*}, \Delta C^{*}{ }_{\mathrm{ab}}\right)$ and global color changes $\left(\Delta E^{*}{ }_{\mathrm{ab}}\right)$ of the surfaces irradiated with the selected laser parameters are shown in Table 3. The differences were computed considering the unpainted granite as reference. Therefore, the lower the $\Delta E^{*}{ }_{\mathrm{ab}}$, the more similar the color of the treated surfaces to the original (i.e., the more effective the laser cleaning). In general, the color change after all the laser treatments was mainly due to a decrease of the $L^{*}$ coordinate, indicating a darkening of the color of the rock. In parallel, the other color parameters showed different trends depending on the irradiation wavelength/s as well as the color of the graffiti:

- Blue graffiti. Negative $\Delta a^{*}$ and $\Delta b^{*}$ values were obtained, indicating a loss of the original yellowish-brown hue of the rock. Specifically, negative $\Delta b^{*}$ values (particularly for the $1064 \mathrm{~nm}$ cleaning tests) are indicative of unsuccessful cleaning level and blue graffiti remnants on the 
surface. The most satisfactory result, based on CIELAB characterization, corresponds to the cleaning with $355 \mathrm{~nm}\left(\Delta E_{\mathrm{ab}}^{*}=6.15\right.$ CIELAB units).

- Black graffiti. Noticeable positive $\Delta b^{*}$ values were obtained upon IR irradiation as well as its $F_{\mathrm{IR}} / F_{\mathrm{UV}}=3 / 1$ combination. This change indicates an increase to the intensity of the original yellowish color of the rock. Conversely, negative $\Delta b^{*}$ values were obtained upon single UV irradiation and its $F_{\mathrm{IR}} / F_{\mathrm{UV}}=1 / 3$ combination, indicating fading of the original granite color. These results agree with stereomicroscopic observations. The surfaces cleaned with the IR beam or the combined beams with the higher IR contribution, exhibited increased $\Delta E_{a b}^{*}(>11$ CIELAB units), while the surfaces treated with the UV beam or the combined beams with the higher UV contribution, showed lower $\Delta E_{\mathrm{ab}}^{*}(\sim 9$ CIELAB units) and, in consequence, they are closer to the reference. In this sense, the treatment with UV irradiation would be the most effective in removing the black graffiti.

- Silver graffiti. The darkening observed by stereomicroscope is confirmed from the values of $\Delta L^{*}$, and consequently the $\Delta E^{*}$, which are the highest ones among all the samples (up to 25 CIELAB units). This darkening effect was most intense upon UV irradiation (as an individual beam or combined with IR). Moreover, $1064 \mathrm{~nm}$ resulted into the lowest $\Delta E_{\mathrm{ab}}^{*}$ (14.84 CIELAB units), although the cleaning of silver graffiti was not satisfactory.

Table 3. Colorimetric differences $\left(\Delta L^{*}, \Delta a^{*}, \Delta b^{*}, \Delta C^{*}{ }_{\mathrm{ab}}\right)$ and global color changes $\left(\Delta E_{\mathrm{ab}}^{*}\right)$ of the surfaces irradiated with the selected conditions. The differences were computed considering the unpainted granite as reference. Detailed info on fluence values and pulses for each irradiation condition can be found in Table 2.

\begin{tabular}{ccccccc}
\hline Graffiti & Wavelength & $\boldsymbol{\Delta} \boldsymbol{L}^{*}$ & $\boldsymbol{\Delta} \boldsymbol{a}^{*}$ & $\boldsymbol{\Delta} \boldsymbol{b}^{*}$ & $\boldsymbol{\Delta} \boldsymbol{C}_{\mathbf{a b}}^{*}$ & $\boldsymbol{\Delta} \boldsymbol{E}_{\mathbf{a b}}^{*}$ \\
\hline \multirow{3}{*}{ Blue } & $\mathrm{IR}$ & -10.67 & -4.40 & -5.98 & -3.60 & 13.00 \\
& $\mathrm{UV}$ & -5.60 & -0.59 & -2.48 & 1.10 & 6.15 \\
& $\mathrm{~F}_{\mathrm{IR}} / \mathrm{F}_{\mathrm{UV}}: 1 / 3$ & -6.63 & -0.59 & -2.56 & -0.07 & 7.13 \\
\hline \multirow{4}{*}{ Black } & $\mathrm{IR}$ & -11.66 & 1.26 & 7.72 & 8.26 & 14.04 \\
& $\mathrm{UV}$ & -8.49 & 0.14 & -0.65 & -8.45 & 8.52 \\
& $F_{\mathrm{IR}} / F_{\mathrm{UV}}: 3 / 1$ & -11.78 & 0.68 & 1.88 & 2.58 & 11.95 \\
& $F_{\mathrm{IR}} / F_{\mathrm{UV}}: 1 / 3$ & -9.29 & 0.00 & -1.95 & -3.82 & 9.50 \\
\hline \multirow{3}{*}{ Silver } & $\mathrm{IR}$ & -14.59 & 0.56 & 2.67 & 5.29 & 14.84 \\
& $\mathrm{UV}$ & -25.92 & 0.28 & -2.60 & -5.27 & 26.05 \\
& $F_{\mathrm{IR}} / F_{\mathrm{UV}}: 3 / 1$ & -23.39 & 0.60 & -0.52 & 2.10 & 23.41 \\
\hline
\end{tabular}

Taking into account that the cleaning effectiveness is characterized by low $\Delta E_{\mathrm{ab}}^{*}$, it is confirmed that none of the irradiation tests could recover the original color of the granite. However, this does not mean that laser cleaning was totally ineffective; a possible explanation for the high $\Delta E_{\mathrm{ab}}^{*}$ values measured is the amount of graffiti that has penetrated the cracks, being consequently inaccessible to the laser beam. In this sense, the use of $\Delta E^{*}$ ab as an index of effectiveness of graffiti laser cleaning on granite should be applied with caution. However, the information offered by the $L^{*}, a^{*}$ and $b^{*}$ variations allows us to attribute the color changes detected at certain observations (i.e., the presence of remains for blue graffiti, the enhancement of yellowish coloration on the surface after black paint extraction and silver graffiti remains).

FTIR spectra of all surfaces (reference granite and graffiti, as well as the surfaces irradiated with the selected conditions) are depicted in Figure 5. In blue and black graffiti paints spectra (Figure 5a,b), the alkyd nature is reflected on the bands at $2925 \mathrm{~cm}^{-1}$ and $2854 \mathrm{~cm}^{-1}$ corresponding to $\mathrm{C}-\mathrm{H}$ asymmetric stretching vibrations of alkanes [15,32]. From $1717 \mathrm{~cm}^{-1}$ to $1070 \mathrm{~cm}^{-1}$, bands assigned to esters were detected: $1717 \mathrm{~cm}^{-1}$ corresponding to the stretching vibration $\mathrm{C}=\mathrm{O}$ and bands in the 1651-1071 $\mathrm{cm}^{-1}$ corresponding to $\mathrm{C}-\mathrm{O}-\mathrm{C}$ group vibration stretching. The detection of a strong band at $1290 \mathrm{~cm}^{-1}$ and several effects around $1200-1100 \mathrm{~cm}^{-1}$ indicated the possible presence of esters 
of unsaturated aliphatic fatty acids [32]. In case of the silver graffiti paint (Figure 5c), reflectance bands assigned to functional groups $\mathrm{C}-\mathrm{H}, \mathrm{C}=\mathrm{O}$ and $\mathrm{C}-\mathrm{O}-\mathrm{C}$ are less represented in accordance with previous literature [15], thus confirming the polyethylene nature of this paint.

The evaluation of the cleaning efficiency using FTIR spectra yielded de following results:

- Blue graffiti (Figure 5a): Effects assigned to blue paint (functional groups $\mathrm{C}-\mathrm{H}, \mathrm{C}=\mathrm{O}$ and $\mathrm{C}-\mathrm{O}-\mathrm{C}$ ) were identified only on the surfaces cleaned with IR radiation. On samples treated with UV beam (either single UV or simultaneously with IR), only the bands typical of silicates were detected.

- Black graffiti (Figure 5b): FTIR spectra of functional groups assigned to this paint were detected only on the surfaces treated with the single IR beam and its $F_{\mathrm{IR}} / F_{\mathrm{UV}}=3 / 1$ combination. These organic remains could contribute to the increase of the yellowish tone of the rock detected by stereomicroscopy and confirmed by color measurements.

- Silver graffiti (Figure 5c): The spectra obtained does not allow us to consistently evaluate the effectiveness of the cleaning of this paint, because the high reflectance of the Al-rich particles masked the bands of the organic groups of the binder. Despite this, after laser cleaning the bands at $2925 \mathrm{~cm}^{-1}$ and $2854 \mathrm{~cm}^{-1}$ (corresponding to C-H asymmetric stretching vibrations of alkanes) are slightly increased. This indicates that a significant amount of Al particles has been extracted, thus making it possible for the FTIR to detect the organic fraction of the paint which remains on the surface (and is also observed under stereomicroscopy and SEM).

FTIR spectra of the surfaces painted with blue and black graffiti cleaned with IR radiation or its $F_{\mathrm{IR}} / F_{\mathrm{UV}}=3 / 1$ combination, showed a band around $3740 \mathrm{~cm}^{-1}$ which is attributed to $\mathrm{O}-\mathrm{H}$ groups coordinated with metals [32]. Rivas et al. [15] attributed this effect to the laser induced modification of the hydration state of the iron oxyhydroxides, covering the fissures in this stone. The yellowish-brown color of Vilachán granite is due to the presence of Fe oxyhydroxides that cover the fissures, textural feature typical on Hercynian granites of NW Iberian Peninsula [33]. The intensification of this coloration after the laser treatment could be attributed to a change of the hydration level of this Fe-rich oxyhydroxides, in addition to the presence of organic remains on the surfaces.

SEM-EDS analysis allowed the identification of graffiti remains on the surfaces by means of the detection of the characteristic chemical elements of each paint (see Section 3.3. and Figure 3): $\mathrm{C}, \mathrm{Si}, \mathrm{Ti}$ and $\mathrm{Mg}$ in the case of blue, $\mathrm{C}$ in the case of black and $\mathrm{C}$ and $\mathrm{Al}$ in the case of silver graffiti. The overall results are discussed here:

- Blue graffiti (Figure $6 \mathrm{a}-\mathrm{c}$ ). No remains of this paint were found on the surfaces treated with the simultaneous use of both wavelengths $\left(F_{\mathrm{IR}} / F_{\mathrm{UV}}\right.$ ratio $\left.1 / 3\right)$ (Figure $\left.6 \mathrm{c}\right)$. Therefore, this condition is identified as the most efficient one, in accordance with stereomicroscopy and FTIR. Conversely, on areas irradiated with the IR beam, paint remains were detected (Figure 6a) and, at lesser extent, remains were also found on the surface irradiated with the UV beam (Figure 6b).

- Black graffiti (Figure 7). C-rich deposits (solid black deposits in Figure 7a) and a C-rich film (greyish coloration in Figure 7a) were detected on the surfaces irradiated at $1064 \mathrm{~nm}$. On areas treated with the combined wavelengths at $F_{\mathrm{IR}} / F_{\mathrm{UV}}$ ratio $3 / 1$ (Figure $7 \mathrm{c}, \mathrm{d}$ ), even though a C-rich film was also detected (Figure 7d), less amount of C-rich deposits was identified (Figure 7c) comparatively to the surface treated with $1064 \mathrm{~nm}$ irradiation (Figure 7a). On areas irradiated with the two wavelengths simultaneously at $F_{\mathrm{IR}} / F_{\mathrm{UV}}$ ratio $1 / 3$ (Figure $7 \mathrm{e}, \mathrm{f}$ ) only discrete $\mathrm{C}$-rich deposits were identified (solid black remains on Figure 7e). Finally, on the sample treated with single UV beam, no C-rich remains were detected (Figure $7 \mathrm{~b}$ ).

- Silver graffiti (Figure 6d-f). After IR irradiation (Figure 6d), a C-rich film was clearly detected on the surface. Irradiation with UV (either as a single beam-Figure 6e-or in combination with IR-Figure 6f), this film was accompanied by a large number of $\mathrm{Al}$ particles distributed throughout the surface. This finding was also reported in [15] after the treatment of the same graffiti with a Nd:YVO 4 at $355 \mathrm{~nm}$. 
(a)

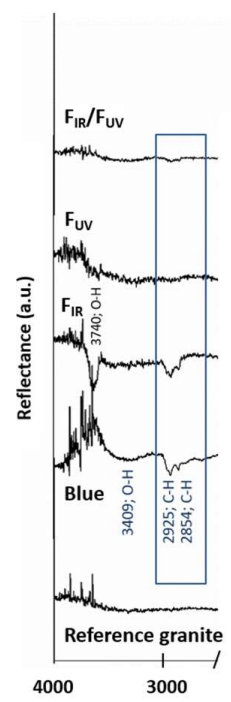

(b)

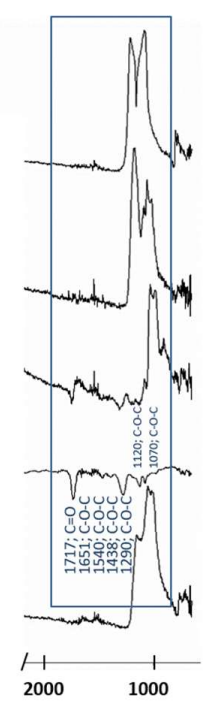

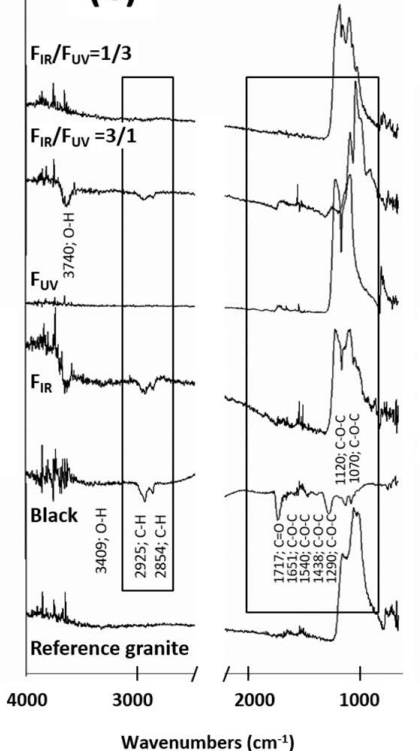

(c)

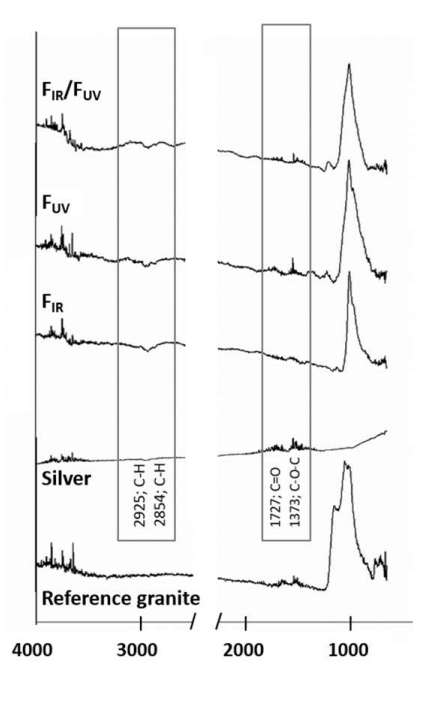

Figure 5. Fourier transform infrared (FTIR) spectra (reflectance mode) of the surfaces irradiated with the selected conditions with $1064 \mathrm{~nm}$ (IR), $355 \mathrm{~nm}$ (UV) and their simultaneous use (in various $F_{\mathrm{IR}} / F_{\mathrm{UV}}$ ratios) to remove blue (a); black (b) and silver (c) graffiti paints. FTIR spectra of the reference granite and the graffiti paints are also shown for comparative purposes. Detailed information on fluence values and pulses for each irradiation condition can be found in Table 2.
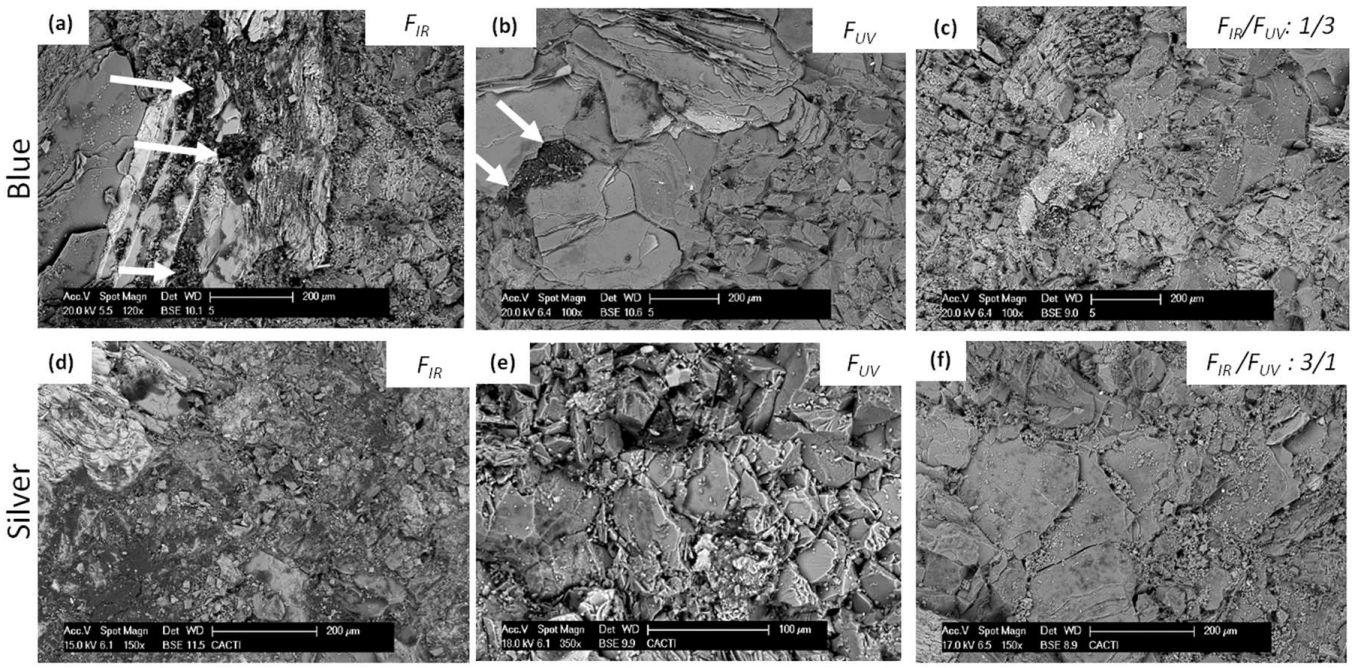

Figure 6. SEM micrographs of the areas treated with the selected conditions to extract blue (a-c) and silver (d-f) graffiti paints using $1064 \mathrm{~nm}(\mathrm{IR})(\mathbf{a}, \mathbf{d}) ; 355 \mathrm{~nm}(\mathrm{UV})(\mathbf{b}, \mathbf{e})$ and their simultaneous use (c,f). Graffiti remains are pointed out with arrows. Detailed information on fluence values and pulses for each irradiation condition can be found in Table 2.

On the areas treated with the selected conditions of single IR (Figure 8a) and UV (Figure 8b) beams, melting of biotite was confirmed. Conversely, the simultaneous use of both wavelengths seemed to slightly reduce the melting of biotite planes, making it possible to find intact (non-melted) exfoliation planes (Figure 8c,d).

Figure 9 shows the arithmetic average height $\left(R_{\mathrm{a}}, \mu \mathrm{m}\right)$ of the areas treated with the selected laser conditions for each individual wavelength (IR and UV) and their simultaneous use $\left(F_{\mathrm{IR}} / F_{\mathrm{UV}}\right)$. 
$R_{\mathrm{a}}$ for the reference granite and for the non-irradiated graffiti painted surfaces are also shown for comparative purposes.
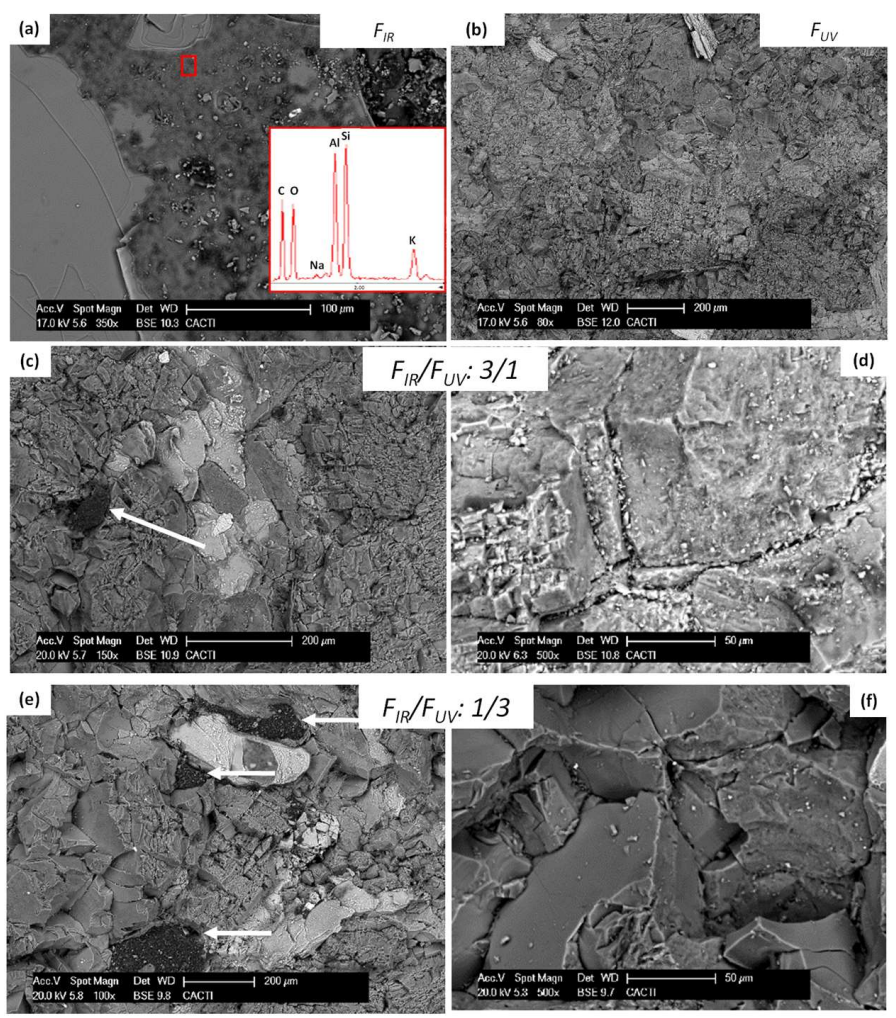

Figure 7. SEM micrographs of the areas treated with the selected conditions to extract black graffiti using $1064 \mathrm{~nm}$ (IR) (a); $355 \mathrm{~nm}$ (UV) (b) and their simultaneous use: (c,d) $F_{\mathrm{IR}} / F_{\mathrm{UV}}$ ratio $3 / 1$ and $(\mathbf{e}, \mathbf{f}) F_{\mathrm{IR}} / F_{\mathrm{UV}}$ ratio $1 / 3$. Graffiti remains are pointed out with arrows. Detailed information on fluence values and pulses for each irradiation condition can be found in Table 2.
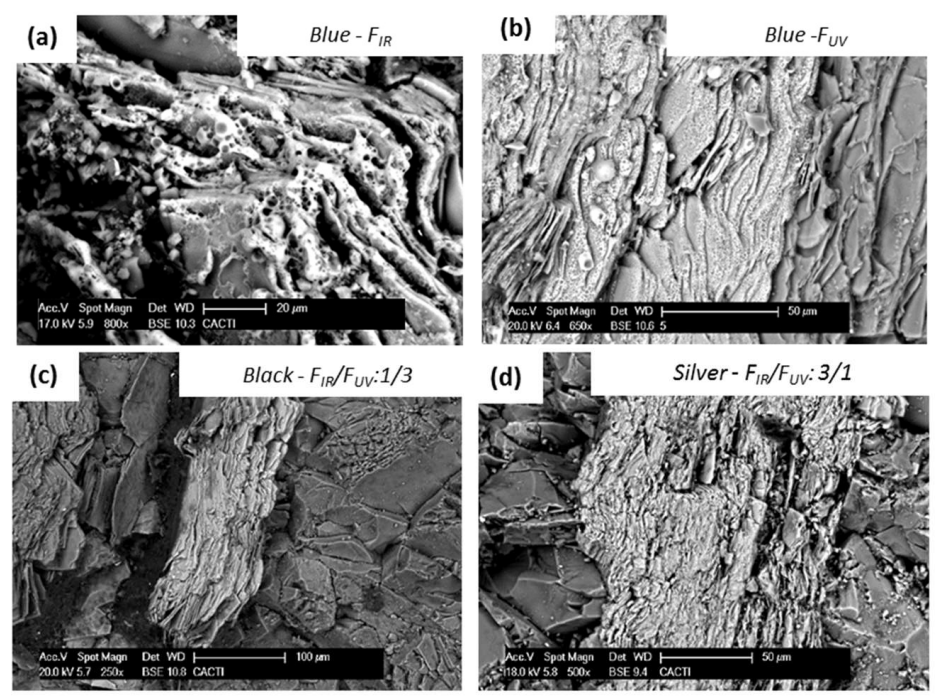

Figure 8. SEM micrographs of biotite grains on some areas treated with the selected conditions to extract blue $(\mathbf{a}, \mathbf{b})$, black $(\mathbf{c})$ and silver $(\mathbf{d})$ graffiti. $(\mathbf{a}, \mathbf{b})$ show melted biotite grains and $(\mathbf{c}, \mathbf{d})$ intact biotite grains. Detailed information on fluence values and pulses for each irradiation condition can be found in Table 2. 
Non-irradiated graffiti painted surfaces show $R_{\mathrm{a}}$ values slightly lower than the reference granite. Therefore, the paint has a smoothing effect on the original roughness of the stone. This is more evident for the blue and black graffiti paints; the highest $R_{\mathrm{a}}$ of the silver painted surface could be related to the existence of the Al-rich particles dispersed in the C-matrix, as was observed by SEM in the cross sections while blue and black paints were continuous, homogeneous, and fine-grained.

After the cleaning of blue graffiti with the selected conditions, an increase of the Ra values was detected. The surface that showed a value for $R_{\mathrm{a}}$ closer to the value of the reference granite was the one treated with the two wavelengths simultaneously $\left(F_{\mathrm{IR}} / F_{\mathrm{UV}}\right.$ ratio $\left.1 / 3\right)$; on the contrary, the surfaces cleaned with $1064 \mathrm{~nm}$ showed the highest $R_{\mathrm{a}}$ indicating damage to the rock.

The surface roughness of the black graffiti surfaces irradiated with $355 \mathrm{~nm}$ as well as the simultaneously combined beams $\left(F_{\mathrm{IR}} / F_{\mathrm{UV}}: 1 / 3\right.$ and $\left.3 / 1\right)$ was slightly reduced. This could be due to (1) the laser induced melting of biotite, which would soften the surface or (2) the presence of a homogeneous film covering the surface, remnant of the graffiti paint.

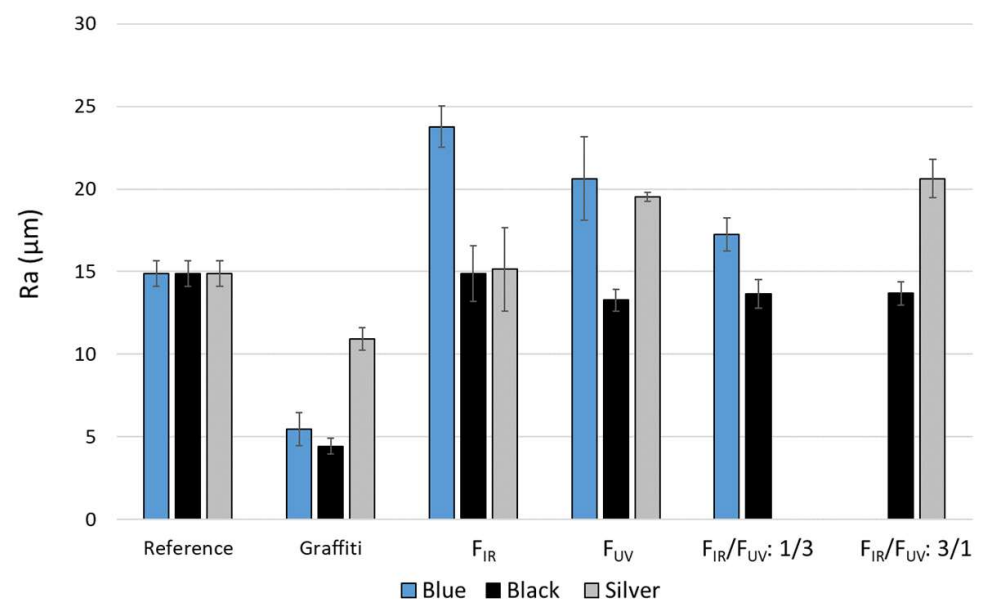

Figure 9. $R_{\mathrm{a}}(\mu \mathrm{m})$ of the areas treated with the selected laser conditions to extract blue, black, and silver graffiti paints using $1064 \mathrm{~nm}$ (IR), $355 \mathrm{~nm}$ (UV) and their simultaneous use at different $F_{\mathrm{IR}} / F_{\mathrm{UV}}$ ratios. The roughness values of the reference granite and non-irradiated graffiti surfaces are provided. Standard deviation values are also shown. Detailed information on fluence values and pulses for each irradiation condition can be found in Table 2 (For interpretation of the references to color in this figure legend, the reader is referred to the web version of this article).

Observation of cross-sections under SEM (Figure 10) allows us to better interpret the $R_{\mathrm{a}}$ results. Surfaces painted with blue graffiti and treated with laser (Figure 10c,d) clearly displayed a higher roughness (in terms of number of peaks and valleys) than the reference granite (Figure 10a). Graffiti tremains can be detected into fissures and cracks after $1064 \mathrm{~nm}$ irradiation.
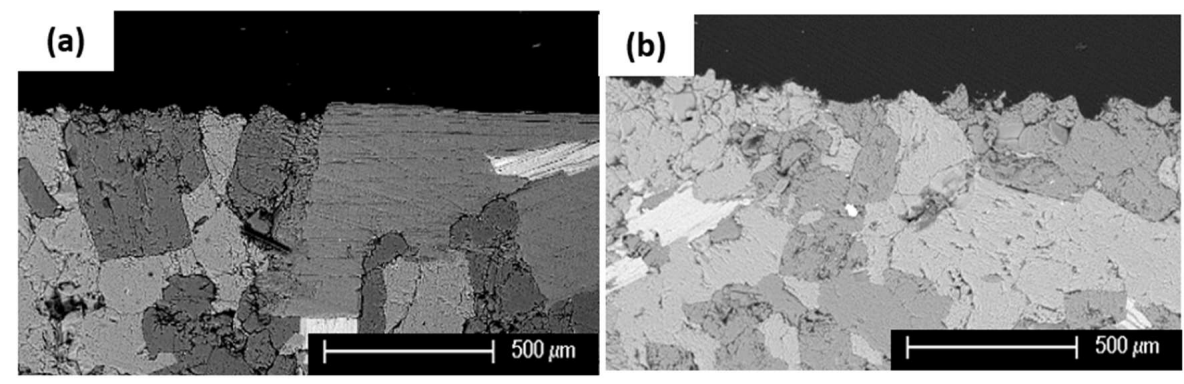

Figure 10. Cont. 

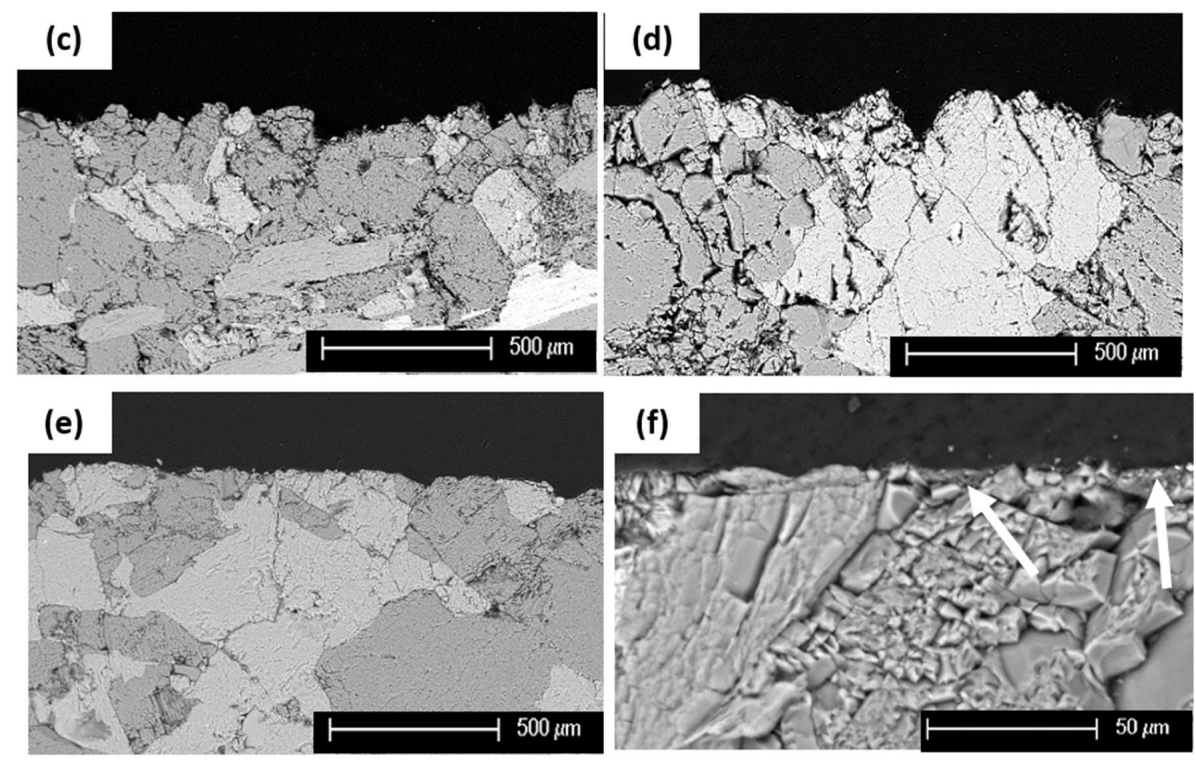

Figure 10. SEM micrographs of the cross sections of the reference granite (a) and some surfaces treated with the selected laser conditions to extract silver (b-with UV radiation), blue (c-with IR radiation; and $\mathbf{d}$-with $F_{\mathrm{IR}} / F_{\mathrm{UV}}: 1 / 3$ ) and black (e-with IR radiation; and $\mathbf{f}$-with $\left.F_{\mathrm{IR}} / F_{\mathrm{UV}}: 3 / 1\right)$. Graffiti remains in (f) are pointed out with arrows. Detailed information on fluence values and pulses for each irradiation condition can be found in Table 2.

Surfaces painted with black graffiti and treated with laser (Figure 10e,f) exhibited a similar (or slightly lower) roughness to the reference granite and no damages to the forming-minerals were identified. SEM allowed us to confirm the existence of a C-rich film on the surface, mainly on the sample treated with $F_{\mathrm{IR}} / F_{\mathrm{UV}}$ ratio 3/1 (graffiti remains are pointed out with arrows in Figure 10f). This result would explain the slightly reduction on $R_{\mathrm{a}}$ values after the laser treatment.

Finally, on surfaces painted with silver graffiti and treated with laser, SEM confirmed the increase of roughness after the laser treatment with all the selected conditions, especially after the UV radiation (Figure 10b).

\section{Discussion}

\subsection{Determination of Damage Thresholds of Granite and Extraction Thresholds of Graffiti Paints}

The fluence threshold values for damage initiation on Vilachán granite upon single-pulse irradiation using the two harmonics of a Q-Switched Nd:YAG laser at $1064 \mathrm{~nm}$ and $355 \mathrm{~nm}$ were determined at $1.1 \mathrm{~J} \cdot \mathrm{cm}^{-2}$ and $0.7 \mathrm{~J} \cdot \mathrm{cm}^{-2}$ respectively. Irradiation at higher fluence values lead to biotite melting and roughness increase. Similar thresholds values were reported by Delgado Rodrigues et al. [22]. These ablation thresholds on granite were determined based on the induced damage to the biotite grains, as this is the most susceptible granitic component to the laser beam [19,22].

For the graffiti paints studied, the extraction thresholds have been found to be below $0.1 \mathrm{~J} \cdot \mathrm{cm}^{-2}$ at $1064 \mathrm{~nm}$ and $355 \mathrm{~nm}$. The only exception is the extraction threshold of blue graffiti at $1064 \mathrm{~nm}$ which was found at $0.5 \mathrm{~J} \cdot \mathrm{cm}^{-2}$. These results conform well both with theoretical calculations (Table 1) and with previous published data, as for example experiments reported by Costela et al [21] where extraction thresholds at $355 \mathrm{~nm}$ were in the range of $0.23-0.27 \mathrm{~J} \cdot \mathrm{cm}^{-2}$, Gomez et al. [20] where extraction thresholds at $1064 \mathrm{~nm}$ were $0.02-0.07 \mathrm{~J} \cdot \mathrm{cm}^{-2}$ and Rivas et al. [15] where extraction thresholds at $355 \mathrm{~nm}$ were laid below $0.07 \mathrm{~J} \cdot \mathrm{cm}^{-2}$, depending on the graffiti color.

The methodology developed for the simultaneous use of the two beams for graffiti removal was based on the limitation that, for any ratio $F_{\mathrm{IR}} / F_{\mathrm{UV}}$, the total laser fluence values $\left(F_{\text {total }}\right)$ should 
not exceed the granite damage thresholds [12], while the relatively low graffiti extraction thresholds allowed for a wide range of combinations.

\subsection{Blue and Black Graffiti Cleaning}

For the blue and black graffiti cleaning experiments, the most satisfactory removal was obtained with the simultaneous use of UV and IR wavelengths at fluence ratio $F_{\mathrm{IR}} / F_{\mathrm{UV}}=1 / 3$ (specifically $0.1 / 0.3 \mathrm{~J} \cdot \mathrm{cm}^{-2}$ ). Stereomicroscopy, FTIR and SEM confirmed the effective paint removal with minimal damage to the granitic forming minerals. In general laser irradiation at UV wavelengths (either alone or in a combined beam with high UV contribution) was found to give satisfactory cleaning results when compared to IR irradiation.

After the treatment of blue painted samples, graffiti remnants were easily visualized under stereomicroscopy and detected by SEM as deposits rich in $\mathrm{C}, \mathrm{Si}$, Ti and $\mathrm{Mg}$. These remains were more abundant after the single IR irradiation. In the case of black painted samples, graffiti remnants were observed under SEM in two forms: (1) C-rich discrete deposits and (2) a diffuse C-rich film. Both types were detected in higher amounts after the single IR irradiation, but the C-rich film was inexistent after the treatment with single $\mathrm{UV}$ and with $F_{\mathrm{IR}} / F_{\mathrm{UV}}$ ratio of $1 / 3$, while it was less visible after the treatment with $F_{\mathrm{IR}} / F_{\mathrm{UV}}$ ratio of $3 / 1$. Therefore, this $\mathrm{C}$-rich film, as residue, seems to be produced mainly under IR wavelength. Its presence only on the laser irradiated black samples highlights a different ablation mechanism for blue and black paints. Thus, considering that the nature of the organic matrix is the same in both graffiti paints, the key factor would be the nature of the pigment (carbon in black graffiti and inorganic particles on blue graffiti). Gómez et al. [20] also reported the importance of the pigment nature on the laser removal effectiveness.

In the black samples, irradiation with IR increased the intensity of the original yellowish hue of the granite. Conversely, after UV treatment, the rock slightly lost its yellowish-brown tone. These changes were not similarly obvious in the case of the blue painted samples, mainly because the blue tonality prevails on a yellowish-brown rock and thus is easily noticeable. Therefore, the persistence of very few graffiti remains would mask the increased intensity of the original hue of the rock. Note that the same coordinate $\left(b^{*}\right)$ expresses both colors, blue and yellow. In case of the black painted samples, the possible remains of black paint would contribute to $L^{*}$ decrease and, for the observer's eyes, they could be misidentified as small biotite grains. Moreover, note that changes in roughness, as was detected by confocal microscopy, can also contribute to color changes [34].

The detected increase of the yellowish hue seems to be produced, as FTIR confirmed, by a modification of the hydration degree of the iron of oxyhydroxilated forms, without underestimating the contribution of the organic remains detected after the laser treatment. This chemical modification took place in both blue and black painted samples treated with IR wavelength, but it was only manifested (visually or from color measurements) on the black painted samples. It would not be the first time that laser generated a chemical modification in granite forming minerals. Urones-Garrote et al. [35] found that laser irradiation of a Nd:YAG at $355 \mathrm{~nm}$ induced fading of the pink hue in Rosa Porriño granite due to changes in the microstructure and composition of feldspar grains, specifically on the $\mathrm{ZnFe}_{2} \mathrm{O}_{4}$ particles present into feldspar.

In conclusion, for our tests, the laser cleaning conditions that resulted into satisfactory paint extraction with minimal damage in the case of blue and black graffiti was the simultaneous combination of the two beams at $F_{\mathrm{IR}} / F_{\mathrm{UV}}=1 / 3$. Moreover, the differences observed in the color and types of remains on the laser irradiated surfaces indicate different ablation process for both paints, being the pigment the component that would mark this difference. It must be also noted here that for the selected optimal cleaning conditions, any color remnants due to local differences in paint thickness can be eventually circumvented by adjusting the number of applied laser pulses, always under the direct control of a reliable monitoring process. 


\subsection{Silver Graffiti Cleaning}

In all experiments involving silver graffiti, a homogenous ablation process could not be achieved, and graffiti paint remained on the surfaces, resulting into discolored (darker and/or more yellowish) surfaces, as also confirmed by stereomicroscopy and color measurements. Similar results have been reported by Rivas et al. working with a different ns laser Nd:YVO 4 at $355 \mathrm{~nm}$ [15]; red, blue, and black colors with alkyd composition were removed satisfactorily, while the silver paint based on polyethylene did not shown its complete extraction. This suggests that the graffiti-granite interaction and subsequently, the graffiti cleaning effectiveness depend on the graffiti binder composition: Polyethylene-based graffiti paints were more difficult to be extracted than the alkyd graffiti. Therefore, further research should be done to clarify this key point.

Considering the results obtained by the radiations tested in this study and their combination, there are certain differences among the laser tested conditions indicating that each wavelength interacted differently with the silver paint. The Al-rich particles detected upon UV irradiation indicate the preferential layer-by-layer removal of the highly absorbed organic medium, resulting into $\mathrm{Al}$ remnants, while on the other hand the detection of a C-rich film to the surfaces irradiated with IR confirms the selective removal of the Al particles. The different ablation mechanisms can be explained with the fact that the two laser wavelengths are differentially absorbed by the paint components (organic binder and Al-rich particles) and thus material removal is different in each case.

This result is associated with ineffective paint extraction and laser induced changes to both the remaining particles and the binder. It must be noted that such effects were not observed on the technical (silver paint on glass) samples where the silver film is extracted, and a very thin translucent organic film remains. Therefore, the contribution of the granitic substrate in the cleaning results should be taken into account, as its presence may trigger secondary phenomena between the involved materials, which may explain these discolored surfaces. For a more practical point of view and considering the ineffectiveness of the experiences of this work to clean this graffiti, further studies must be undertaken, for example, the use of wavelengths that are highly absorbed by Al-rich particles.

\section{Conclusions}

In this work, a comparative study between the single $(1064 \mathrm{~nm}$ or $355 \mathrm{~nm})$ and two wavelengths (1064 $\mathrm{nm}$ and $355 \mathrm{~nm}$ applied simultaneously) ablation methodologies was carried out to determine their suitability for the extraction of graffiti from granite. Initially, the damage thresholds of the granite $\left(1.1 \mathrm{~J} \cdot \mathrm{cm}^{-2}\right.$ for $1064 \mathrm{~nm}$ and $0.7 \mathrm{~J} \cdot \mathrm{cm}^{-2}$ for $\left.355 \mathrm{~nm}\right)$ and the extraction thresholds of the graffiti paints at both wavelengths (below $0.1 \mathrm{~J} \cdot \mathrm{cm}^{-2}$ except for blue graffiti at $1064 \mathrm{~nm}$ which is $0.5 \mathrm{~J} \cdot \mathrm{cm}^{-2}$ ) were determined.

Regarding the two-wavelength laser cleaning methodology, which was adjusted for the specific cleaning challenge, results indicate that the synchronous use of the two beams can clearly enhance the removal of blue and black graffiti in comparison to the single wavelength cleaning tests. Indeed, surfaces irradiated with the two beams at $F_{\mathrm{IR}} / F_{\mathrm{UV}}=1 / 3$ clearly show the superiority of this methodology regarding cleaning effectiveness while any potential damages to the granite (i.e., loss of the characteristic yellowish coloration, roughness increase and biotite melting) were minimized.

On the other hand, the cleaning tests on silver painted granite, given its different composition and morphology, were not satisfactory, leaving a substantial amount of Al-rich particles. Thus, further tests are necessary.

Overall, except for silver, the simultaneous combination of the $1064 \mathrm{~nm}$ and $355 \mathrm{~nm}$ wavelengths resulted in improved cleaning levels and in a reduced substrate damage, when compared to the results of the individual beams and thus further experimentation should be undertaken to optimize this laser cleaning approach.

Acknowledgments: This work has been supported by the Spanish research project BIA2014-54186-R. José Santiago Pozo-Antonio was supported by a postdoctoral contract with the University of Vigo within the framework of the 
2011-2015 Galician Plan for Research, Innovation and Growth (Plan I2C) for 2014. We also acknowledge support of this work by the project "POLITEIA II" (Politismos-Technologia, New Technologies in the Research, Study, Documentation and Access to the Information for Cultural Heritage Objects and Monuments II) (MIS 5002478) which is implemented under the "Action for the Strategic Development on the Research and Technological Sector", funded by the Operational Programme "Competitiveness, Entrepreneurship and Innovation" (NSRF 2014-2020) and co-financed by Greece and the European Union (European Regional Development Fund).

Author Contributions: All the co-authors conceived and designed the experiments; José Santiago Pozo-Antonio and Athanasia Papanikolaou performed the experiments; José Santiago Pozo-Antonio, Athanasia Papanikolaou, Paraskevi Pouli and Teresa Rivas analyzed the data; José Santiago Pozo-Antonio, Athanasia Papanikolaou, Kristalia Melessanaki, Paraskevi Pouli and Teresa Rivas wrote the paper.

Conflicts of Interest: The authors declare no conflict of interest.

\section{References}

1. GRAFFITAGE: Development of a New Anti-Graffiti System, Based on Traditional Concepts, Preventing Damage of Architectural Heritage Materials. SSP (Policy Oriented Research) of the Sixth European Programme of the European Commission. FP6-2003-SSP3-513718. 2008. Available online: https: / / cordis. europa.eu/result/rcn/52034_es.html (accessed on 27 February 2018).

2. Sanmartín, P.; Cappitelli, F.; Mitchell, R. Current methods of graffiti removal: A review. Constr. Build. Mater. 2014, 71, 363-374. [CrossRef]

3. GRAFFOLUTION: Awareness and Prevention Solutions against Graffiti Vandalism in Public Areas and Transport. SSP (Policy Oriented Research) of the Seventh European Programme of the European Commission. FP7-SEC-2013-1. 2016. Available online: https:/ / trimis.ec.europa.eu/project/awareness-and-preventionsolutions-against-graffiti-vandalism-public-areas-and-transport (accessed on 27 February 2018).

4. Gomes, V.; Dionísio, A.; Pozo-Antonio, J.S. Conservation strategies against graffiti vandalism on cultural heritage stones: Protective coatings and cleaning methods. Prog. Org. Coat. 2017, 113C, 90-109. [CrossRef]

5. Carmona-Quiroga, P.M.; Panas, I.; Svensson, J.E.; Johansson, L.G.; Blanco-Varela, M.T.; Martínez-Ramírez, S. Protective performances of two anti-graffiti treatments towards sulfite and sulfate formation in $\mathrm{SO}_{2}$ polluted model environment. Appl. Surf. Sci. 2010, 257, 852-856. [CrossRef]

6. Carmona-Quiroga, P.M.; Jacobs, R.M.; Martínez-Ramírez, S.; Viles, H.A. Durability of anti-graffiti coatings on stone: Natural vs. accelerated weathering. PLoS ONE 2017, 12, e0172347. [CrossRef] [PubMed]

7. Cooper, M. Laser Cleaning in Conservation: An Introduction; Butterworth-Heinemann: Oxford, UK, 1998.

8. Fotakis, C.; Anglos, D.; Zafiropulos, V.; Georgiou, S.; Tornari, V. Lasers in the Preservation of Cultural Heritage: Principles and Applications; Brown, R.G.W., Pike, E.R., Eds.; CRC Press: Boca Raton, FL, USA, 2006.

9. Siano, S.; Giamello, M.; Bartoli, L.; Mencaglia, A.; Parfenov, V.; Salimbeni, R. Laser cleaning of stone by different laser pulse duration and wavelength. Laser Phys. 2008, 18, 27. [CrossRef]

10. Vergès-Belmin, V.; Rolland, O.; Jourd'heuil, I.; Guiavarc'h, M.; Zanini, A. Nd:YAG long Q-switched versus short free running laser cleaning trials at Chartres cathedral, France. Stud. Conserv. 2015, 60, S12-S18. [CrossRef]

11. Iglesias-Campos, M.A.; Prada-Pérez, J.L. Actual laser removal of black soiling crust from siliceous sandstone by high pulse repetition rate equipment: Effects on surface morphology. Mater. Constr. 2016, 66, e078. [CrossRef]

12. Pouli, P.; Papakonstantinou, E.; Frantzikinaki, K.; Panou, A.; Frantzi, G.; Vasiliadis, C.; Fotakis, C. The two-wavelength laser cleaning methodology; theoretical background and examples from its application on $\mathrm{CH}$ objects and monuments with emphasis to the Athens Acropolis sculptures. Herit. Sci. 2016, 4, 9. [CrossRef]

13. Senesi, G.S.; Carrara, I.; Nicolodelli, G.; Milori, D.M.B.P.; De Pascale, O. Laser cleaning and laser-induced breakdown spectroscopy applied in removing and characterizing black crusts from limestones of Castello Svevo, Bari, Italy: A case study. Microchem. J. 2016, 124, 296-305. [CrossRef]

14. Sanz, M.; Oujja, M.; Ascaso, C.; Pérez-Ortega, S.; Souza-Egipsy, V.; Fort, R.; de los Ríos, A.; Wierzchos, J.; Cañamares, M.V.; Castillejo, M. Influence of wavelength on the laser removal of lichens colonizing heritage stone. Appl. Surf. Sci. 2017, 399, 758-768. [CrossRef]

15. Rivas, T.; Pozo, S.; Fiorucci, M.P.; López, A.J.; Ramil, A. Nd:YVO 4 laser removal of graffiti from granite. Influence of paint and rock properties on cleaning efficacy. Appl. Surf. Sci. 2012, 263, 563-572. 
16. Samolik, S.; Walczak, M.; Plotek, M.; Sarzynski, A.; Pluska, I.; Marczak, J. Investigation into the removal of graffiti on mineral supports: Comparison of nanosecond Nd:YAG laser cleaning with traditional mechanical and chemical methods. Stud. Conserv. 2015, 60, S58-S64. [CrossRef]

17. Pozo-Antonio, J.S.; Rivas, T.; Fiorucci, M.P.; López, A.J.; Ramil, A. Effectiveness and harmfulness evaluation of graffiti cleaning by mechanical, chemical and laser procedures on granite. Microchem. J. 2016, 125, 1-9. [CrossRef]

18. Ramil, A.; Pozo-Antonio, J.S.; Fiorucci, M.P.; López, A.J.; Rivas, T. Detection of the optimal laser fluence ranges to clean graffiti on silicates. Constr. Build. Mater. 2017, 148, 122-130.

19. Sanjeevan, P.; Klemm, A.J.; Klemm, P. Removal of graffiti from the mortar by using Q-switched Nd:YAG laser. Appl. Surf. Sci. 2007, 253, 8543-8553. [CrossRef]

20. Gomez, C.; Costela, A.; García-Moreno, I.; Sastre, R. Comparative study between IR and UV laser radiation applied to the removal of graffitis on urban buildings. Appl. Surf. Sci. 2006, 252, 2782-2793. [CrossRef]

21. Costela, A.; García-Moreno, I.; Gómez, C.; Caballero, O.; Sastre, R. Cleaning graffitis on urban buildings by use of second and third harmonic wavelength of a Nd:YAG laser: A comparative study. Appl. Surf. Sci. 2003, 207, 86-99.

22. Delgado Rodrigues, J.; Costa, D.; Mascalchi, M.; Osticioli, I.; Siano, S. Laser ablation of iron-rich black films from exposed granite surfaces. Appl. Phys. A 2017, 117, 365-370. [CrossRef]

23. Fiorucci, M.P.; Lamas, J.; López, A.J.; Rivas, T.; Ramil, A. Laser cleaning of graffiti in Rosa Porriño granite. Proc. SPIE Int. Soc. Opt. Eng. 2011, 8001, 80014A. [CrossRef]

24. Pouli, P.; Oujja, M.; Castillejo, M. Practical issues in laser cleaning of stone and painted artefacts: Optimization procedures and side effects. Appl. Phys. A 2012, 106, 447-464. [CrossRef]

25. IGME (Instituto Geológico y Minero de España). Mapa geológico de España. Serie Magna, E-1:50.000, 2nd ed.; Ministerio de Industria y Energía: Madrid, Spain, 1985. (In Spanish)

26. RILEM. Commission 25 PEM. Protection et Erosion des Monuments. Recommandations provisoires. Essais recommandés pour mesurer l'altération des pièrres et évaluer l'efficacité des méthodes de traitement. Test No. II. 1: Open Porosity. Matériaux de Constructions 1980, 13. (In French)

27. Kliem, W.; Lehmann, G. A reassignment of the optical absorption bands in biotites. Phys. Chem. Miner. 1979, 4, 65-75. [CrossRef]

28. ISO 4288 Geometrical Product Specifications (GPS)—Surface Texture: Profile Method, Terms, Definitions and Surface Texture Parameters; International Organization for Standardization: Geneva, Switzerland, 1999.

29. CIE S014-4/E: 2007 Colorimetry Part 4: CIE 1976 L $^{*} a^{*} b^{*}$ Colour Space, Commission Internationale de l'eclairage; CIE Central Bureau: Vienna, Austria, 2007.

30. Prieto, B.; Sanmartín, P.; Silva, B.; Martínez-Verdú, F. Measuring the color of granite rocks: A proposed procedure. Color Res. Appl. 2010, 35, 368-375. [CrossRef]

31. Liu, J.M. Simple technique for measurements of pulsed Gaussian-beam spot sizes. Opt. Lett. 1982, 7, $196-198$. [CrossRef] [PubMed]

32. Socrates, G. Infrared and Raman Characteristic Group Frequencies: Tables and Charts, 3rd ed.; John Wiley and Sons: Hoboken, NJ, USA, 2001.

33. Escuder, J.; Carbonell, R.; Martí, D.; Pérez-Estaún, A. Interacción fluido-roca a lo largo de las superficies de fractura: Efectos mineralógicos y texturales de las alteraciones observadas en el Plutón Granítico de Albalá, SO del Macizo Hercínico Ibérico. Boletín Geológico y Minero 2001, 112, 59-78. (In Spanish)

34. Yonehara, M.; Matsui, T.; Kihara, K.; Isono, H.; Kijima, A.; Sugibayashi, T. Experimental relationships between surface roughness, glossiness and color of chromatic colored metals. Mater. Trans. 2005, 4, 1027-1032. [CrossRef]

35. Urones-Garrote, E.; López, A.; Ramil, A.; Otero-Díaz, L.C. Microstructural study of the origin of color in Rosa Porriño granite and laser cleaning effects. Appl. Phys. A 2011, 104, 95-101. [CrossRef]

(C) 2018 by the authors. Licensee MDPI, Basel, Switzerland. This article is an open access article distributed under the terms and conditions of the Creative Commons Attribution (CC BY) license (http://creativecommons.org/licenses/by/4.0/). 